\title{
Interférences
}

Ars scribendi

$9 \mid 2016$

Varia

\section{La mémoire des figures impériales chez Claudien}

\section{Charlotte Tournier}

\section{OpenEdition}

Journals

Édition électronique

URL : http://journals.openedition.org/interferences/5830

DOI : 10.4000/interferences.5830

ISSN : $1777-5485$

Éditeur

HiSoMA - Histoire et sources des Mondes antiques

Référence électronique

Charlotte Tournier, «La mémoire des figures impériales chez Claudien », Interférences [En ligne], 9 | 2016, mis en ligne le 18 janvier 2018, consulté le 15 septembre 2020. URL : http://

journals.openedition.org/interferences/5830; DOI : https://doi.org/10.4000/interferences.5830

Ce document a été généré automatiquement le 15 septembre 2020.

Tous droits réservés 


\title{
La mémoire des figures impériales chez Claudien
}

\author{
Charlotte Tournier
}

\section{Introduction}

1 Plusieurs passages des poèmes politiques de Claudien ont pu être qualifiés de « miroirs des princes ${ }^{1}$ ", dans lesquels des figures impériales antérieures sont des exempla à l'appui du conseil politique donné à l'empereur Honorius : parmi elles se distinguent en particulier Théodose, qui a légué son pouvoir à ses fils et qui apparait pour rappeler ce legs et indiquer quelle est la bonne manière de régner sur l'Empire, et Trajan, considéré depuis Pline ${ }^{2}$ comme l'un des modèles, si ce n'est le modèle consacré de l'optimus princeps dans l'Antiquité tardive ${ }^{3}$. Claudien fait allusion à ce dernier par des mentions explicites, mais aussi par des reprises intertextuelles (voir ci-dessous), et il le présente comme un ancêtre d'Honorius. Ainsi, au travers de ces multiples références, le poète entreprend de dessiner pour le tout jeune Prince d'Occident la figure du bon empereur.

2 Les exempla mythologiques ou historiques appartiennent à la topique panégyrique ${ }^{4}$ : ils situent le destinataire dans la lignée des grands hommes de Rome, ils renforcent le consensus entre l'auteur, le destinataire et le public, et ils inscrivent le discours présent dans le genre du discours panégyrique. Faut-il en conclure que Claudien use de ces références comme de simples topoi encomiastiques et rhétoriques, qui concourent à décrire Honorius comme le nouvel optimus princeps de l'Empire ${ }^{5}$ ? Nous voudrions explorer la manière dont la mémoire des empereurs précédents est utilisée par Claudien au service d'un discours politique plus complexe que cela sur la Rome de son temps. En effet, dire qu'Honorius descend de Trajan et/ou de Théodose revient à superposer deux idées : la légitimité dynastique d'une part, et la légitimité acquise par le mérite personnel du bon prince d'autre part. Or cette question de la légitimité, et de ce qui la fonde, pose particulièrement problème à l'époque où écrit Claudien : elle se voit incarnée par deux hommes, Honorius et le régent Stilicon, qui ont le pouvoir de manière effective, voire trois si l'on compte Arcadius, l'aîné de Théodose à qui celui-ci a 
confié la partie orientale de l'Empire, et même quatre avec Rufin puis Eutrope, tous deux ministres d'Arcadius. Il convient ainsi de se pencher sur la représentation que Claudien donne de cette situation politique bien particulière: comment mettre en scène le fait que le souverain légitime n'ait aucune envergure politique, alors que le régent peut-être auto-proclamé, et dont la place est largement contestée dans l'Empire, possède toutes les qualités requises pour être un excellent gouvernant ${ }^{6}$ ? Le problème se complique encore dans un contexte immédiat ou au moins récent d'usurpations, de guerres civiles et d'invasions barbares. Il convient également de préciser le fonctionnement de cette forme qu'est le miroir des princes: son rôle est-il encomiastique, parénétique, idéologique? Qui doit-il convaincre, de l'auditoire ou de l'Empereur?

3 Pour tenter d'éclairer ces aspects, nous nous proposons d'analyser la manière dont Claudien convoque dans ses poèmes politiques les Empereurs antérieurs à 395, année de l'accession au trône d'Honorius. Parce que notre étude sera centrée sur leur rôle dans la construction de la figure impériale, nous nous limiterons aux poèmes consacrés à Honorius: les trois panégyriques impériaux, et les poèmes nuptiaux écrits pour célébrer les noces d'Honorius et de Marie ${ }^{7}$. Notre démarche sera chronologique, car l'un des objectifs que nous nous proposons est de montrer comment Claudien sait faire évoluer son propos selon les circonstances - ce qui n'en fait pas un poète de circonstance, nous le verrons.

\section{Le Panégyrique pour le troisième consulat d'Honorius, ou l'enfance de l'art}

4 La composition puis la récitation du Panégyrique pour le troisième consulat d'Honorius dans les premiers jours de l'année $396^{8}$ s'inscrivent dans un contexte historique et politique $^{9}$ bien particulier. Théodose est mort depuis un an (il meurt à Milan le 17 janvier 395) ; les Barbares (Alaric en particulier) menacent les frontières de l'Empire; le pouvoir de l'Empereur défunt a été légué à ses deux fils (Arcadius, âgé de dix-huit ans, et Honorius, qui en a onze), mais l'aîné, en sa qualité d'Augustus senior, est en position de revendiquer une part de l'Empire plus importante que celle qui lui est échue effectivement, alors que les vues de Stilicon, tuteur d'Honorius à l'Ouest, se heurtent à celles de Rufin, tuteur d'Arcadius à l'Est. Pour Claudien, désormais «chantre de la politique de Stilicon ${ }^{10}$ ", l'enjeu est alors double : il s'agit d'une part d'imposer Honorius face à Arcadius malgré son très jeune âge, et d'autre part de rendre légitimes la place de Stilicon et ses prétentions à la régence sur les deux moitiés de l'Empire ${ }^{11}$. Or cela est bien délicat : d'une part car il n'existe aucun testament officiel de Théodose susceptible de confirmer les vues de Stilicon, et d'autre part car, contrairement à son frère, Arcadius est en âge de régner ${ }^{12}$.

5 La préface du poème donne le ton, en présentant l'image de deux frères aigles dont le père éprouve la force et châtie celui qui est plus faible que l'autre. Bien que les quatre derniers vers invitent à ne mettre l'image en rapport qu'avec le seul Claudien, c'est déjà affirmer qu'entre deux frères le droit d'aînesse n'est rien : ce sont les uires et l'ingenium propres à chacun qui font la vraie noblesse (acie nobiliore, dit le vers 12) et qui justifient la place de potens et d'heres - termes lourds de sens dans le contexte de la succession de Théodose. Le début du poème proprement dit inaugure ici un thème qui reviendra souvent ${ }^{13}$ dans les autres poèmes politiques de Claudien : la qualité de porphyrogénète 
d'Honorius. Né dans la pourpre, Honorius doit régner. Mais en outre, comme l'explique J.-L. Charlet, c'est ici un moyen de faire du Prince d'Occident au moins l'égal de son frère oriental : «si Arcadius a par rapport à Honorius la précellence de l'âge et de l'accession à l'Empire (il est consul prior), Honorius peut s'enorgueillir d'être né fils d'empereur, alors qu'Arcadius est né fils de simple citoyen, puisque Théodose n'était pas encore empereur à sa naissance ${ }^{14} 》$.

6 À l'instar du pater aigle, c'est alors la figure de Théodose qui va jouer un grand rôle pour ce qui est d'affirmer la place d'Honorius ${ }^{15}$. Elle apparaît au vers 24 , et ne disparaît qu'au vers 191 : entre les deux, elle traverse tout le texte. Elle se situe sur deux plans à la fois: sur le plan privé, en tant que figure paternelle, et sur le plan public ou politique, en tant que figure impériale. Claudien insiste sur sa paternité : il est nommé par lui pater ou parens, et lui-même, au vers 38 , se désigne à la $3^{\mathrm{e}}$ personne sous le terme de parens. Cette appellation est importante : parce qu'elle insiste bien sûr sur l'autorité que représente Théodose pour Honorius, mais aussi car, comme nous allons le voir, elle va servir à désigner Stilicon plus d'une fois, faisant du général semi-vandale un double de Théodose. Responsable de l'éducation de son jeune fils, il apparaît comme le bras d'Honorius trop jeune pour agir (v. 88-89) : il préfigure ce que sera la relation entre Honorius et Stilicon telle que Claudien n'aura de cesse de nous la décrire, c'est-à-dire fondée sur la scission entre la fonction honorifique attribuée à Honorius d'une part, et le gouvernement effectif endossé par Stilicon d'autre part. Les vers suivants sont révélateurs (Claudien, Panégyrique pour le troisième consulat d'Honorius 83-89) :

Ille uetat rerumque tibi commendat habenas

et sacro meritos ornat diademate crines.

Tantaque se rudibus pietas ostendit in annis,

sic aetas animo cessit, quererentur ut omnes

imperium tibi sero datum. Victoria uelox

auspiciis effecta tuis. Pugnastis uterque:

tu fatis genitorque manu.

"Ton père te l'interdit, mais il te confie les rênes des affaires et orne du diadème sacré tes cheveux, qui l'ont mérité. Si grand est l'amour pour la patrie qui s'est révélé en tes tendres années, ainsi ton âge le céda à ton cœur, que tous déploraient que l'Empire te fût confié si tard. Sous tes auspices, la victoire arriva prestement. Vous avez combattu ensemble : toi par les destins, ton père par son bras. »

7 Tout le problème, s'il y en a un, réside seulement dans la trop grande jeunesse d'Honorius et son arrivée prématurée à la fonction suprême. Cela revient à dire qu'il ne saurait être question de remettre en cause son mérite personnel : il existe évidemment (et son ardeur à partir au combat au moment de la guerre civile entre Eugène et Théodose en témoigne) - mais en puissance. C'est que Claudien a ici la tâche de «justifier une nomination de type dynastique sans véritable utilité politique ou militaire ${ }^{16} »$. Décrire l'anatrophê du jeune Prince ne revient donc pas seulement pour Claudien à sacrifier à la topique encomiastique : par un phénomène de compensation, cette description représente un moyen de louer Honorius même s'il est trop jeune pour avoir mérité la louange ${ }^{17}$.

8 Il est finalement tout naturel qu'Honorius, trop jeune pour régner seul à cette date, passe de la coupe de son père à celle de Stilicon ${ }^{18}$. C'est ce qui apparaît dans l'une des reconstitutions par Claudien de l'entretien au cours duquel Théodose aurait confié à Stilicon la régence pour ses deux fils ${ }^{19}$. Les deux discours de Théodose représentent les seules délégations de parole du poème, ce qui les rend d'autant plus frappantes ${ }^{20}$. Dans le second, le poète nous offre un compte rendu sans intermédiaire de la scène du 
passage de flambeau de Théodose à Honorius - ce qui est nécessaire pour accréditer un entretien sans témoin ${ }^{21}$. La formule qui introduit le discours résume bien quel est l'enjeu ici, celui d'une transmission qui cherche à se donner une légitimité, si ce n'est dynastique, du moins familiale: Vt uentum ad sedes, cunctos discedere tectis / dux iubet et generum compellat talibus ultro ${ }^{22}$. Théodose est l'Empereur, dux, qui confie la protection de ses fils à son gendre, generum - le terme est mis en valeur à la coupe. Le vers 158 résume cette alliance en une formule frappante, rejetée en début de vers: ut ducis, ut soceri. Cette transmission se justifie doublement par les qualités de Stilicon: d'une part par ses exploits en temps de guerre (v. 144) ${ }^{23}$, d'autre part par sa fides en tant de paix (v. 145) - le terme de fides reviendra pour désigner la loyauté absolue de Stilicon envers Théodose et ses fils ${ }^{24}$. Stilicon est, d'emblée, l'homme providentiel, ce que met particulièrement en valeur le rejet de te sine au vers 146 : Bellipotens Stilicho, cuius mihi robur in armis, / pace probata fides - quid enim per proelia gessi / te sine ${ }^{25}$ ? Mais en outre, si les vers 144-150 insistent essentiellement sur la valeur militaire de Stilicon (qui le rapproche de Théodose), tout particulièrement avec l'apostrophe liminaire (bellipotens Stilicho), l'évocation de son mariage aux vers 154-157 en fait un membre de la famille des deux jeunes empereurs. Stilicon est invité à devenir un autre Théodose. Néanmoins, malgré ses qualités de chef, c'est la fonction de père seule qu'il est censé endosser ici. Foue; protege ; indue mente patrem ; dilige ; te custode : son rôle est celui d'un protecteur. Les vers 51-60 apportent un argument de plus en sa faveur; Théodose, toujours lui, présente à son fils l'exemple de son propre père, Théodose comes, qui, sans être empereur, était un excellent $d u x$, et le père d'un empereur - tout comme peut l'être Stilicon ${ }^{26}$ : Quoque magis nimium pugnae inflammaret amorem, / facta tui numerabat aui ${ }^{27}$. Légitimer Stilicon en en faisant un membre de la famille revient en outre à désavouer Rufin, qui, en l'absence d'un testament officiel de Théodose, aurait autant de prétention sur Arcadius que Stilicon, mais ne peut se targuer d'un tel lien. Claudien ne donne toutefois pas plus de précisions concernant le statut politique de Stilicon ${ }^{28}$, et pour cause : le concept de régence n'existe pas à Rome à l'époque, et si, dans les faits, c'est lui qui prend les décisions en lieu et place du petit Honorius ${ }^{29}$, cette position-là est, tout simplement, illégitime - a fortiori en ce qui concerne Arcadius, qui a dix-huit ans.

Honorius n'est néanmoins pas mis de côté - et on voit mal en effet comment il pourrait en être autrement dans un panégyrique qui lui est destiné. Puisqu'il faut bien que Claudien lui accorde un rôle, il incarne la fonction impériale, ce que Stilicon ne saurait faire. Bien plus, il semble l'incarner à lui seul, car la présence d'Arcadius est évacuée autant que cela est possible ${ }^{30}$. Né dans la pourpre, c'est à Honorius que reviennent «les rênes des affaires " (v. 83) et le "diadème sacré » (v. 84). C'est à lui que Théodose souhaite confier l'Empire avant de mourir : distulit Augusto cupido se credere caelo, / dum tibi pacatum praesenti traderet orbem ${ }^{31}$. Il faut noter qu'il n'est pas question ici d'Arcadius, pourtant Auguste tout comme son frère, et même nommé avant lui. À Stilicon la victoire par la valeur militaire, à Honorius la victoire par le seul fait de son existence. On voit qu'ici la dimension parénétique ${ }^{32}$ de l'éloge est de fait fort discrète : il ne s'agit pas encore d'inciter Honorius à se hisser à la hauteur des modèles qu'on lui présente, mais bien davantage d'entériner et de justifier la situation dans laquelle Honorius est dépossédé du gouvernement concret au profit de Stilicon (sans que cela soit dit explicitement), étant bien entendu que, malgré ses qualités, il est encore trop jeune pour l'assumer lui-même. Tandis que le poète loue le Prince, c'est donc Théodose ${ }^{33}$, figure d'autorité suprême, qui assume l'éloge de Stilicon: à travers la question de la transmission, les deux soulignent la continuité de la fonction impériale. 


\section{Comment être Trajan quand on n'est qu'Honorius ? Le Panégyrique pour le quatrième consulat d'Honorius}

10 Claudien récite le Panégyrique pour le quatrième consulat d'Honorius deux ans plus tard. La relation de l'Occident avec l'Orient est toujours un problème car, si Rufin n'est plus une menace pour Stilicon, Eutrope lui a succédé, il a fait déclarer le régent hostis publicus, et Arcadius est totalement sous sa coupe ${ }^{34}$. La dissension entre les deux parties de l'Empire est gravissime : en Afrique, Gildon, allié d'Arcadius, bloque les exportations de blé vers l'Occident et place l'Empire sous la menace d'une guerre civile. Mais surtout, Honorius est sur le point d'atteindre les quatorze ans qui doivent faire de lui un souverain autonome : est-il apte à régner ? Et dans ces conditions, que devient Stilicon?

11 Après avoir exprimé ses vœux pour l'année à venir, Claudien fait référence dès le vers 19 à la famille Ulpia: Haud indigna coli nec nuper cognita Marti / Vlpia progenies et quae diademata mundo/ sparsit Hibera domus ${ }^{35}$. Il reprend à son compte l'idée de la prétendue filiation entre Trajan et Théodose ${ }^{36}$, qui, dans les faits, s'appuie essentiellement sur leur origine espagnole commune ${ }^{37}$. L'éloge du genos est un lieu attendu en tête d'un discours encomiastique: il est normal que Claudien loue les ancêtres d'Honorius. Mais pourquoi faire un tel saut chronologique de Théodose à Trajan? Claudien n'est pas le premier à établir un lien entre Trajan et Théodose, et il convient de comprendre comment ce lien a été figuré avant lui pour évaluer la manière dont Claudien utilise les figures de Trajan et de Théodose en vue de légitimer Honorius et/ou Stilicon. F. Chausson consacre tout un chapitre de son ouvrage Stemmata aurea : Constantin, Justine, Théodose à l'analyse des revendications généalogiques et de la conception de la légitimité impériale de Théodose. Ce qu'il souligne en premier lieu, c'est que la figure de Trajan est indéfectiblement liée à l'idée du choix du meilleur. Comme le révèle un parallèle intéressant entre Thémistius, 14, 3, 182 B-C, et Dion Cassius, 68, 3, 4-4, 2, le choix du meilleur au moment de la nomination de Théodose par Gratien rappelle la nomination de Trajan par Nerva. F. Chausson met en lumière des points communs d'importance capitale pour notre propos : "Tous les éléments sont là : âge de l'empereur qui fait le choix, élection due à la valeur, choix d'un militaire en charge, mépris des liens de parenté, hispanité ${ }^{38} »$. C'est un thème de première importance, que Thémistius a tenu à souligner dès l'avènement de Théodose : dans le choix de Gratien, «l'intérêt de l'État semble avoir primé sur les liens du sang ${ }^{39}$ ». De même, en 14, 8, 204 B - 205 B. Thémistius loue Théodose «parce qu'il a préféré confier le consulat à une autre personne que son propre fils ${ }^{40}$ ", à un moment où Arcadius était déjà grand, ce qui le relie à la figure de Trajan, «son ancêtre et le fondateur de sa lignée $^{41} »$. Mais au fil du règne de Théodose, le lignage dynastique prend une autre dimension, non plus seulement symbolique, mais généalogique, qui vient confirmer les parallèles politiques affichés. Ce lien a visiblement été recherché par Théodose luimême, et revendiqué par exemple via la statuaire : il aurait fait placer dans son palais à Constantinople des bustes des Antonins, " comme autant d'imagines symbolique [sic] de ses ancêtres et de points de référence de son pouvoir impérial ${ }^{42}$ ", allant donc au-delà d'une simple origine espagnole commune. Les difficultés militaires de l'époque dans la région du Danube rendaient pertinente l'image de Théodose en nouveau Trajan, image inspirée à la fois par la patrie commune, et par le parallèle entre deux généraux issus de l'ordre sénatorial et élevés au pouvoir par le choix d'un prince auquel ils n'étaient 
pas liés par le sang ${ }^{43}$. F. Chausson note cependant qu'entre 382 et 385 la référence aux Antonins se voit modifiée : l'image de Trajan disparait progressivement, tandis que le rattachement se fait plutôt avec Hadrien, Marc Aurèle et Antonin. Il met cette évolution en rapport avec deux événements, d'une part avec la disparition de Gratien, «sur qui était fondé le rapprochement exemplaire avec le choix du meilleur dans la tradition de Nerva et Trajan ", et d'autre part avec l'élévation d'Arcadius à l'Augustat: " c'est une nouvelle dynastie qui s'affirme et qui éprouve le besoin de se situer non plus par rapport à une élection mais par rapport à une continuité familiale vécue sur la longue durée. Les liens unissant entre eux Hadrien, Marc et Antonin - qui étaient des liens familiaux étroits renforcés par l'adoption - deviennent plus représentatifs des ambitions de la nouvelle dynastie que la filiation adoptive rattachant Nerva à Trajan $^{44}$.» Un peu plus tard, Pacatus ${ }^{45}$, dans le Panégyrique de Théodose qu'il récite en 389, s'appuie sur l'origine espagnole commune de Trajan et de Théodose (et fait de l'Espagne la patrie des plus grands hommes), sans pour autant faire du premier l'ancêtre du second. Toutefois (Pacatus, Panégyrique de Théodose 4, 4-5 ) 46 $^{4}$ :

Sint, ut scribitur, Gargara prouentu laeta triticeo, Meuania memoretur armento, Campania censeatur monte Gaurano, Lydia praedicetur amne Pactolo, dum Hispaniae uni quidquid ubique laudatur assurgat. Haec durissimos milites, haec experientissimos duces, haec facundissimos oratores, haec clarissimos uates parit, haec iudicum mater, haec principum est. Haec Traianum illum, haec deinceps Hadrianum misit imperio, huic te debet imperium. Cedat his terris terra Cretensis parui Iouis gloriata cunabulis et geminis Delos reptata numinibus et alumno Hercule nobiles Thebae. Fidem constare nescimus auditis : deum dedit Hispania quem uidemus.

"Qu'il en soit comme il est écrit : que le Gargare soit riche en récoltes de froment, que Mevania soit célèbre par ses troupeaux de bœufs, que la Campanie doive sa renommée au mont Gaurus, que la Lydie soit réputée pour le fleuve du Pactole, pourvu qu'à l'Espagne seule le cède à tout ce qu'on loue partout ailleurs. C'est elle qui enfante les soldats les plus résistants, les généraux les plus expérimentés, les orateurs les plus éloquents, les poètes les plus illustres: elle est la mère des gouverneurs et des empereurs. C'est elle qui a donné à l'empire l'illustre Trajan et ensuite Hadrien, c'est d'elle que l'empire t'a reçu. Que devant cette terre s'effacent la terre de Crète, fière du berceau de Jupiter enfant, et Délos où les divins jumeaux firent leurs premiers pas et Thèbes illustre pour avoir nourri Hercule. Nous ne savons rien de l'authenticité de ces traditions, mais l'Espagne nous a donné un dieu que nous voyons. "

Plus loin, il fait parler l'allégorie de la Respublica, dans une prosopopée où elle se plaint auprès de Théodose de ses résistances à accepter la magistrature suprême alors que la patrie est en danger et que lui seul peut la sauver (Pacatus, Panégyrique de Théodose 11, 4-7) :

Parumne me, Theodosi, hactenus distulere fata ut tu insuper temptes moras augere fatorum ? An nescis rem tuam per momenta consumi? Nescis me tibi tuis que decrescere? Quicquid atterit Gothus, quicquid rapit Chunus, quicquid aufert Halanus, id olim desiderabit Arcadius. Perdidi infortunata Pannonias, lugeo funus Illyrici, specto excidium Galliarum. Principum senior in tanta bella non sufficit, alter, etsi futurus sit aliquando fortissimus, adhuc tamen paruus est. Tu dubitas excipere collapsam et, ut nihil differas, sero reparandam? Hanc mihi gratiam refers quod te etiam felix desideraui? Quod, cum me Nerua tranquillus, amor generis humani Titus, pietate memorabilis Antoninus teneret, cum moribus Augustus ornaret, legibus Hadrianus imbueret, finibus Traianus angeret, parum mihi uidebar beata quia non eram tua? Quid tu mihi faceres, si iuris tui esses? Orat ecce te dominus meus, orat ecce te dominus adhuc tuus et qui posset cogere mauult impetrare. Imperium quod ab imperatore defertur, tam tibi nolle iam non licet quam uelle non licuit. 


\begin{abstract}
« Est-ce trop peu, Théodose, que les destins m'aient fait attendre jusqu'ici et faut-il encore que tu essaies d'ajouter au retard des destins? Ne sais-tu pas que chaque heure dévore un peu de ton bien ? Ignores-tu que je m'affaiblis pour ton malheur et pour celui de tes enfants? Tout ce que saccage le Goth, tout ce que m'arrache le Hun, tout ce qu'emporte l'Alain, tout cela, Arcadius le regrettera. Infortunée, j'ai perdu mes provinces de Pannonie, je pleure le désastre d'Illyrie, j'ai devant les yeux la ruine des Gaules. L'aîné des princes succombe sous le poids de ces guerres; l'autre, si vaillant qu'il doive être un jour, n'est pour l'heure qu'un enfant. Et toi, tu hésites à soutenir celle qui chancelle et qui sera longue à retrouver ses forces, en admettant que tu ne diffères pas? Est-ce ainsi que tu me sais gré de t'avoir appelé de mes vœux, quand j'étais encore dans la prospérité, au temps où mes maîtres étaient le pacifique Nerva, Titus l'amour du genre humain, Antonin célèbre par sa piété, au temps où Auguste me faisait une parure de vertus, où Hadrien m'initiait aux lois, où Trajan reculait mes frontières, pour avoir cru qu'il manquait quelque chose à mon bonheur parce que je n'étais pas à toi ? Que ferais-tu pour moi, s'il ne tenait qu'à toi? Et voici que mon seigneur et maître t'en prie, voici que t'en prie celui qui est encore ton seigneur et maitre : alors qu'il pourrait te contraindre, il préfère obtenir ton consentement. L'empire qui t'est offert par l'empereur, tu n'as pas plus le droit de le refuser aujourd'hui que tu n'avais <hier> le droit d'y prétendre. »
\end{abstract}

Pacatus place Théodose dans la lignée des grands empereurs des débuts du Principat, et insiste sur son long refus de l'Empire, ce qui est un lieu commun du genre : c'est un moyen de montrer que l'intérêt public passe, aux yeux du souverain loué, avant son intérêt personnel ${ }^{47}$. Ainsi il cherche avant tout à montrer que le Prince n'a obtenu le pouvoir que grâce à ses vertus propres ${ }^{48}$ : te nec ambitus nec occasio nec propinquitas principem creauerunt. Nam et eras a familia imperatoris alienus et adsciscebaris tertius et cogebaris inuitus : inuitus, inquam ${ }^{49}$.

Que signifie le recours à cet exemplum pour Claudien? S'agit-il d'un simple parallèle encomiastique ${ }^{50}$ visant à exalter le prestige d'Honorius? D'un moyen commode pour créer le consensus autour de l'idée de continuité en faisant appel à la mémoire collective? Pour A. Cameron, Claudien en fait un usage tout à fait topique :

Panegyrists regularly exhorted their addressees to imitate the virtues of the "good" Emperors, Trajan and Titus, Pius and Marcus - and avoid the vices of their "bad" counterparts, Nero and Tiberius. Claudian fits exactly into this pattern. Emperors are divided up into good or bad, and only the stock examples of each quoted. Of the good ones, he has most to say about Trajan, but this is for the special reason that, as a Spaniard, Trajan was by a courtly fiction held to be a distant ancestor of Theodosius and Honorius ${ }^{51}$.

On peut toutefois se demander ce qui justifie ici le choix particulier de Trajan. De plus, la comparaison avec la manière dont son héritage est utilisé dans le genre épidictique avant Claudien montre que ce dernier lui fait subir un traitement bien particulier. D'un côté, on a le jeune Honorius, pâle copie de son père ${ }^{52}$, mais qui ne peut se prévaloir que du titre de ce dernier pour justifier son trône, alors même que la figure de l'empereur enfant n'est pas forcément bien vue ${ }^{53}$. De l'autre, nous avons Stilicon, qui, malgré toutes ses qualités, ne peut pas se hisser jusqu'au pouvoir suprême : Théodose, à la fin de son règne, a mis en avant une transmission dynastique du pouvoir et a choisi ses fils pour lui succéder ${ }^{54}$, alors que Stilicon n'est pas un descendant de la famille impériale. Certes, Théodose ne l'était pas non plus, mais il appartenait à une famille sénatoriale, tandis que Stilicon est «à moitié barbare ${ }^{55}$ ». Dans ces circonstances, comment faire quand mérite et ascendance impériale ne sont pas réunis dans une seule et même personne? 
dien recrée au début de son panégyrique une sorte d'arbre généalogique resplendissant de gloire, depuis l'Océan ${ }^{56}$ jusqu'à Théodose, en passant par Trajan puis par Théodose comes, l'auus, invoqué en raison de ses victoires militaires. Théodose, lui, est nommé genitor ${ }^{57}$, et il dépasse la gloire de son père, car ses conquêtes, encore plus importantes, lui ont valu la pourpre impériale (Claudien, Panégyrique pour le quatrième consulat d'Honorius 41-48) :

Sed laudes genitor longe transgressus auitas

subdidit Oceanum sceptris et margine caeli

clausit opes, quantum distant a Tigride Gades,

inter se Tanais quantum Nilusque relinquunt.

Haec tamen, innumeris per se quaesita trophaeis,

non generis dono, non ambitione potitus :

digna legi uirtus. Vltro se purpura supplex

obtulit et solus meruit regnare rogatus.

«Mais ton père a dépassé de loin les louanges gagnées par ton aïeul : il a soumis l'Océan à son sceptre et a donné le ciel comme frontière à son pouvoir, qui renferme tout ce que l'on trouve entre le Tigre et Gadès, tout ce qui existe entre le Nil et le Tanaïs. Ces contrées, toutefois, obtenues en d'innombrables trophées par lui-même, il ne les a pas reçues en héritage ni par la brigue : c'est sa valeur qui a été digne d'être choisie. D'elle-même la pourpre s'est offerte à lui en le suppliant, et, quand on le lui demanda, lui seul mérita de régner. "

7 La métrique met en valeur l'idée du mérite : digna legi uirtus est en rejet, meruit à la coupe. Le parallélisme du vers 46 insiste bien là-dessus, et il constitue un écho formel renvoyant aux mots de Pline ${ }^{58}$. Comme dans le panégyrique précédent, la uirtus semble ici être avant tout d'ordre militaire ${ }^{59}$. Cette idée de mérite, associée à l'image du futur empereur que l'on doit supplier pour qu'il accepte enfin de régner, place Théodose dans la lignée politique du bon empereur. Suit alors le long récit de ses prouesses de chef d'État et de sauveur de la Patrie ${ }^{60}$, propres à le hisser à la fonction d'exemplum pour les siècles à venir (Hinc saecula discant/ indomitum nihil esse pio tutumue nocenti ${ }^{61}$ ) - on pense alors au bellipotens Stilicho du Panégyrique pour le troisième consulat d'Honorius. À partir du vers 111, Claudien décrit plutôt son action politique, dans la droite ligne de Trajan selon ce qu'en rapporte Pline : incarnant la pietas et la clementia, respectueux des droits des citoyens, sachant reconnaître les mérites, confirmé dans sa fonction par l'amour du peuple et de l'armée.

Après avoir ainsi loué ses ancêtres, Claudien passe à Honorius lui-même au vers 121, et aborde, comme il se doit au début d'un discours d'éloge, la question de sa naissance. Celle-ci est étroitement reliée à ce qui précède, particulièrement par le fait que la transition de Théodose à Honorius s'effectue au milieu d'un même vers. Mais au lieu de se servir de ce lien pour rehausser le prestige du jeune Prince, le poète souligne plutôt l'écart qui existe entre lui et son glorieux aïeul. Si Théodose s'est montré digne de son appartenance à la gens Ulpia et a obtenu le pouvoir, c'est donc par ses exploits militaires et sa vertu, non par l'intrigue ou par la naissance. Pourtant, au sujet de son fils, l'accent est mis, précisément, sur sa naissance dans la pourpre : l'idée apparaît deux fois, au vers 125 puis au vers 140 . Honorius se voit même doté de droits sur l'Orient (Claudien, Panégyrique pour le quatrième consulat d'Honorius 127-131) :

\section{[...] Hispania patrem}

auriferis eduxit aquis, te gaudet alumno

Bosphorus. Hesperio de limine surgit origo,

sed nutrix Aurora tibi; pro pignore tanto

certatur, geminus ciuem te uindicat axis. 
«L'Espagne avec ses fleuves d'or a engendré ton père, le Bosphore se réjouit de te voir son enfant. Tes racines sont au seuil de l'Hespérie, mais c'est l'Aurore qui fut ta nourrice; on rivalise pour un enfant si cher, et chaque moitié du monde te réclame comme son citoyen.»

19 Les vers 203-204 décrivent les deux fils de Théodose comme égaux: Laetior augurio genitor natisque superbus / iam paribus duplici fultus consorte redibat / splendebatque pio complexus pignora curru ${ }^{62}$. Certes, exalter la naissance d'Honorius peut être une forme de compensation pour les praxeis absentes d'un personnage valeureux mais trop jeune pour avoir accompli de grandes choses. Cependant, on a beau chercher, aucune trace de ses qualités dans le reste du poème, quoi qu'en disent les vers $430-431^{63}$. Au contraire, le poète insiste particulièrement sur le fait que c'est sa naissance qui a valu sa place à Honorius. Les vers 153-158 nous donnent pas moins de cinq manières différentes d'exprimer la même idée, à savoir qu'Honorius a reçu le consulat à sa naissance ${ }^{64}$. La discordance entre la métrique et la syntaxe, qui apparait à travers les multiples rejets qui émaillent tout le passage à partir du vers 149 , ainsi que les oxymores qui expriment de façon frappante des alliances improbables entre les mots de la plus tendre enfance et ceux du pouvoir semblent d'ailleurs figurer l'étrangeté de cette situation (Claudien, Panégyrique pour le quatrième consulat d'Honorius 149-158) :

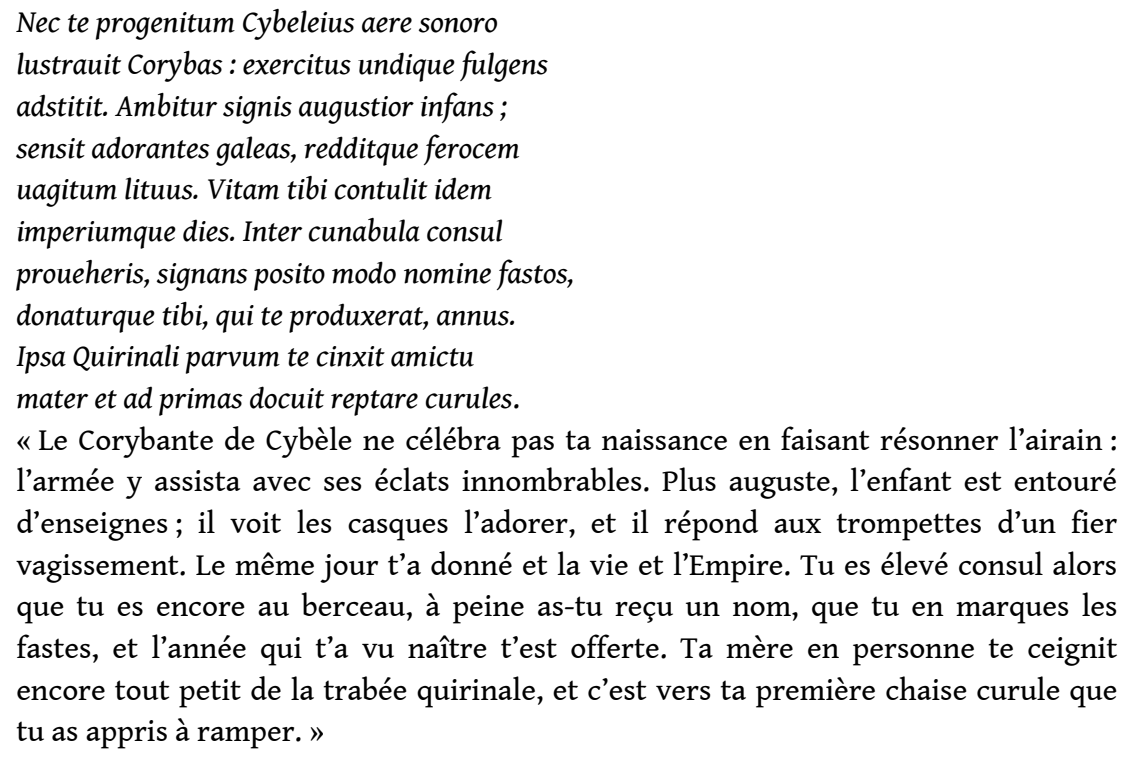

Ce qu'il faut donc comprendre, c'est que, dans le cas d'Honorius, une naissance prestigieuse ne peut suffire à lui assurer la légitimité à la tête de l'Empire d'Occident et les louanges du poète. Trajan n'est pas seulement invoqué car il est l'ancêtre d'Honorius et car la topique encomiastique veut que l'on vante les ancêtres de son sujet : il l'est car il est l'exemple qui montre que la naissance ne fait pas tout, car il s'est constitué une noblesse par la vertu, comme l'a fait ensuite son descendant Théodose. Honorius, né dans la pourpre, doit se souvenir que ses ancêtres ont acquis la pourpre par leur vertu. C'est aussi une invitation lancée à Honorius à s'élever au-dessus de son frère qui, lui, se laisse aller à se contenter de la pourpre. Apparaît donc ici une tension entre la transmission dynastique du pouvoir et l'idée selon laquelle on doit avoir à la tête de l'Empire l'homme le meilleur qui soit ${ }^{65}$. Ainsi, Claudien subvertit l'utilisation de la patrie, des ancêtres et de la naissance comme éléments topiques du discours d'éloge ${ }^{66}$. Contrairement à ce que dit P. Fargues ${ }^{67}$, il n'évoque pas le genos d'Honorius par seul souci de compensation pour des faits d'armes inexistants, comme l'enseignent les rhéteurs. Au lieu de s'en servir à l'appui de l'éloge de son destinataire, il en fait 
autre chose: en rendant manifeste la non-adéquation d'Honorius avec les modèles convoqués, Claudien va au-delà de l'éloge et se sert de la figure de Trajan comme d'un point de départ pour l'expression d'un programme politique. Choisir de mettre en valeur l'héritage de Trajan, au-delà de la topique panégyrique qui veut que l'on aborde la question des ancêtres, c'est placer Honorius dans la lignée du princeps-citoyen.

21 Après la mention de Trajan et le récit de l'enfance d'Honorius, Théodose prend le relais de la uox poetae pour ce qui est d'établir une ligne de conduite politique : au vers 214 s'ouvre une véritable leçon de gouvernement qu'il adresse à son fils, dans ce qui est le plus long des discours que l'on trouve chez Claudien ${ }^{68}$. Il sert donc également de relais entre Trajan et Honorius: ainsi se voient réunies la légitimité par le sang et la légitimité par la vertu politique et militaire. Dans l'article qu'elle a consacré au réemploi de Pline et de Dion par Claudien dans ce panégyrique, C. Ware dresse la liste des qualités qui réunissent Trajan et Théodose ${ }^{69}:$ ils sont nés en Espagne ; ils ont mérité la pourpre sans descendre de la famille impériale; ils n'ont pas gagné leur place par le mariage ou par l'ambition; ils ont pris les commandes du navire de l'État et lui ont évité un désastre; la nature a confirmé leur place; ils partagent les mêmes vertus (la clementia, la ciuilitas). La première chose à laquelle s'attache le père de l'Empereur est d'opposer règne oriental et Principat romain ${ }^{70}$. On voit bien que, lorsque Claudien consent à dire qu'Arcadius et Honorius sont égaux, il faut comprendre qu'Arcadius ne pourra pas être un bon empereur s'il continue à se conduire en roi oriental. Dès le vers 220 , Théodose nous indique le sens que nous devons donner à ce qu'a dit plus tôt le poète, de sorte que le doute ne soit plus permis : si celui-ci a vanté la lignée d'Honorius, c'est que c'était un passage obligé du panégyrique, et certainement pas parce qu'elle représente un réel sujet de louange. Ici, Trajan semble disparaitre : il ne sera plus mentionné explicitement avant le vers 315. C. Ware a cependant montré à quel point la figure de Trajan représente une inspiration explicite et implicite qui traverse tout le poème. Le discours de Théodose y fait massivement référence par le truchement d'une double inspiration, celle de Pline et de son Panégyrique de Trajan dans un premier temps, puis celle de Dion et de ses discours Peri basileias dans un second temps ${ }^{71}$. Théodose enseigne ainsi à son fils que le prince doit maîtriser ses passions; ne pas se contenter de la légitimité donnée par le sang; faire en sorte d'être aimé du peuple; respecter ses propres lois; servir de modèle aux autres. Au vers 316, Théodose nomme Trajan lui-même (Claudien, Panégyrique pour le quatrième consulat d'Honorius 312-320) 72 $^{72}$ :

[...] Quis non per saecula damnat Caesareae portenta domus? Quem dira Neronis

funera, quem rupes Caprearum taetra latebit

incesto possessa seni ? Victura feretur

gloria Traiani, non tam quod Tigride uicto

nostra triumphati fuerint prouincia Parthi,

alta quod inuectus fractis Capitolia Dacis,

quam patriae quod mitis erat. Ne desine tales,

nate, sequi $[. .$.

«Qui ne condamne de siècle en siècle les monstruosités de la maison des Césars ? À qui resteront inconnus les meurtres sinistres de Néron, à qui l'abominable roche de Caprée que possédait un vieillard incestueux ? La gloire de Trajan vivra, non pas tant parce que grâce à la victoire sur le Tigre les Parthes écrasés sont devenus l'une de nos provinces ou parce qu'après avoir brisé les Daces il a été porté au Capitole, que parce qu'il était doux envers la patrie. N'aie de cesse de suivre de tels exemples, mon fils. » 
Deux titres de gloire le caractérisent : le talent militaire contre les Barbares mais, avant toute chose, la douceur envers sa patrie. Autrement dit, on trouve ici l'exacte reproduction de l'image qu'en donnait déjà Claudien quand il parlait en son nom. Sa clémence est d'ailleurs désignée par le même adjectif qu'au vers 113, mitis. Mais la phrase qui suit comporte un élément étrange dans un contexte où l'on ne parle que de Trajan: le pluriel tales. Comme l'explique C. Ware ${ }^{73}$, Trajan est ici dépersonnalisé. Il n'est plus l'homme Trajan, il n'est plus non plus l'ancêtre de la famille, il est cet exemplum de bon princeps... dont les qualités recouvrent tout à fait celles du régent et général Stilicon ${ }^{74}$. D'ailleurs, c'est une leçon d'art militaire qui suit, bien qu'elle ne paraisse pas vraiment être reliée à ce qui précède. La raison en est sûrement à chercher dans le fait que Claudien n'a de cesse, au fil de ses poèmes politiques, de nous décrire Stilicon comme un excellent chef de guerre : ainsi, il renforce encore le parallèle qui peut être établi entre les modèles qu'il donne et celui qui en est la réalisation parfaite en son temps. C. Ware remarque alors qu'Honorius, assimilé à Ascagne, est enfermé dans l'image d'un éternel prince en devenir. Contrairement à ce que la conception que l'on a généralement de la fonction parénétique du «miroir des princes » pourrait nous laisser croire, Claudien cherche en définitive davantage à affirmer le statu quo qu'à conduire Honorius sur la voie du bon gouvernement. Il établit une complémentarité entre Honorius et Stilicon: le premier représente le prestige impérial, il incarne le numen $^{75}$, tandis que le second a la responsabilité du gouvernement. Honorius est un meneur ${ }^{76}$ et un symbole, Stilicon son bras, tout comme l'était Théodose dans le Panégyrique pour le troisième consulat d'Honorius alors que le petit Honorius aspirait à partir à la guerre et que, pour le faire patienter, son père lui confiait «les rênes des affaires ». Ce sont les deux personnages ensemble, le Prince et son régent, qui réunissent ce que signifie la figure de Trajantelle que nous l'ont présentée successivement Claudien et Théodose : la transmission dynastique et le pouvoir accordé à l'optimus uir, qui sont les deux conditions d'un pouvoir légitime ${ }^{77}$. Et en effet, on comprend bien que, malgré les qualités indéniables de Stilicon, évincer Honorius est impensable. Claudien n'entend pas faire remplacer Honorius par Stilicon: il le dit explicitement, et il insiste plusieurs fois sur la fides du général envers Théodose ou envers Honorius. Stilicon n'est pas Trajan ${ }^{78}$. Mais, si l'on permet à Honorius d'assumer à lui seul le pouvoir, que devient Stilicon? Claudien doit ménager un équilibre entre les deux.

Cet équilibre repose en partie sur un usage subtil de l'énonciation, en particulier dans le long passage qui suit la leçon de Théodose, qui tend à confondre les trois protagonistes que sont Théodose, Honorius et Stilicon, le premier étant représenté comme la source du pouvoir légitime des deux autres. Entre les deux discours de son père, Claudien met dans la bouche d'Honorius les paroles qu'il doit tenir s'il suit le programme que lui soumet le poète par ce truchement (v. 353-369) ${ }^{79}$ : c'est l'engager puisque, dans le cadre de la récitation officielle d'un panégyrique impérial, l'empereur ne peut décemment pas interrompre l'orateur pour lui signifier son désaccord. Mais tout ce qui va suivre, jusqu'à la fin du poème, va viser à appuyer l'idée selon laquelle Honorius est encore trop immature pour remplir seul ce programme, et qu'il a donc besoin de l'appui de Stilicon. La peinture du Prince enfant dans le Panégyrique pour le troisième consulat d'Honorius, qui s'expliquait par l'âge qui était le sien au moment de la récitation, se voit reprise ici, mais dans des circonstances différentes qui en modifient le sens : il devient un «éternel mineur ${ }^{80}$ ». En effet, ce n'est pas l'Honorius de 398 qui 
parle dans le passage que nous venons de citer : Claudien ne fait pas parler le fantôme de Théodose comme il le fera dans La Guerre contre Gildon, mais il choisit l'analepse et rend compte d'une conversation qu'aurait pu tenir Théodose de son vivant. Alors, parce qu'Honorius parle comme un enfant ${ }^{81}$, il justifie cette fois lui-même les réserves du poète. À son tour, quand il lui répond, Théodose justifie le fait qu'Honorius ne règne pas seul (Claudien, Panégyrique pour le quatrième consulat d'Honorius 369-374) ${ }^{82}$ :

[...] Delibat dulcia nati

oscula miratusque refert : "Laudanda petisti ;

sed festinus amor. Veniet robustior aetas;

ne propera. Necdum decimas emensus aristas

aggrederis metuenda uiris : uestigia magnae

indolis agnosco. [...]"

«Il effleure son enfant de doux baisers et, plein d'admiration, il répond: "Ta

demande est louable; mais ton désir est trop pressé. Un âge plus robuste viendra;

ne te précipite pas. Tu n'as pas encore vu dix moissons que déjà tu veux

entreprendre des travaux que même des hommes craindraient : je reconnais là la

marque d'un grand caractère [...]" "

L'expression laudanda petisti est particulièrement intéressante, car on peut y déceler une épaisseur d'énonciation : derrière Théodose, c'est Claudien qui parle, et qui dit que ce qu'il y a de louable chez Honorius, ce sont ses intentions, et seulement elles. Après l'échange entre Théodose et son fils, le poète reprend la parole, et il apostrophe le premier à partir du vers 428. Comment alors comprendre les vers 430-431, où il affirme que le fils surpasse dorénavant le père (Iam natus adaequat / te meritis et, quod magis est optabile, uincit $\left.{ }^{83}\right)$ ? Est-ce là une contradiction avec tout ce qui précède ? Ce qui suit laisse à penser que ce n'est pas le cas, car l'éloge qu'on lit ensuite fait de Stilicon la raison des succès d'Honorius. Pour ce faire, Claudien superpose les trois personnages, Théodose, Honorius et Stilicon, en créant des effets de flou : qui est le sujet de recusat au vers $434^{84}$ ? Cette $3^{\mathrm{e}}$ personne peut se comprendre de deux manières: soit elle se rapporte au natus du vers 430 , et c'est ce qu'on peut comprendre à la première lecture, car depuis le début il est question de Théodose et d'Honorius, soit elle se rapporte à la dernière personne dont il a été fait mention, à savoir Stilicon, clipeum defensoremque ${ }^{85}$. En ne le nommant pas, mais en le désignant seulement par une périphrase, Claudien rend plus aisée sa superposition avec Honorius. De même, on se demande qui est le sujet de iubes au vers $440^{86}$. Parce que la dernière apostrophe explicite du poète était destinée à Théodose, le sujet, qui peut sembler être Honorius au premier abord, peut aussi bien être son père. Aux vers $448-449^{87}$, Honorius est désigné à la $3^{\mathrm{e}}$ personne par son nom, et l'identité de la personne à laquelle se rapporte tuum [...] nomen n'est pas forcément très claire. De plus, tout le passage qui relate la campagne sur le Rhin de 396 et la campagne en Grèce de $397^{88}$ mélange de manière étrange temps du présent et temps du passés ${ }^{9}$. On le voit, Claudien fait en sorte que le glissement de l'adresse de Théodose à Honorius s'effectue de manière insensible. Ce faisant, il nous dit que l'action de Stilicon n'est pas seulement le fait d'Honorius qui se reposerait sur lui par faiblesse : il s'agit aussi de la volonté de Théodose. Ainsi, qui est ducem nostrum au vers $446^{90}$ ? Ce peut être à la fois Théodose, Honorius, ou encore Stilicon. Les vers qui suivent tendraient à confirmer cette dernière interprétation, car ce sont ses exploits dont il est question: il est le ille du vers 453 , puisque c'est à la $2^{\mathrm{e}}$ personne que le poète parle d'Honorius. Alors le poète continue à louer Honorius en s'adressant directement à lui. Mais ce n'est pas pour ce qu'il a accompli qu'il le loue : c'est soit pour ce que Stilicon a accompli, soit pour ce qu'il a accompli avec Stilicon. Les campagnes militaires dont il 
est question, Honorius en a donné l'ordre (iubes, v. 440 ; hortaris, v. $460^{91}$ ), mais Stilicon les a réalisées (v. 459-483). C. Ware remarque au vers 476 l'ambiguïté de per te, qui peut se rapporter à Honorius, mais aussi à Stilicon (Claudien, Panégyrique pour le quatrième consulat d'Honorius 474-477) :

Gens, qua non Scythicos diffusior ulla Triones incoluit, cui paruus Athos angustaque Thrace, cum transiret, erat, per te uiresque tuorum fracta ducum lugetque sibi iam rara superstes. «La race qui était la plus étendue parmi celles qui habitaient le Nord de la Scythie, pour qui le mont Athos était trop petit, et la Thrace trop étroite quand elle les franchissait, la voici brisée par toi et par la force de tes chefs, pleurant sur le peu qu'il lui reste. »

Elle écrit :

In per te, Claudian could be addressing either Stilicho or Honorius. As he continues to praise the man before whom the barbarian falls in allegiance, who chooses the best generals in war and magistrates in peace, who has driven out false accusers, reformed the taxes, husbands the wealth of the country, and has the full loyalty of the army, the words seem far more applicable to Stilicho than Honorius. Only after fifty lines of Stilicho's achievements are we told that the subject is really Honorius, and the reminder comes in terms stressing his youth: te miles nutritor amat, "The soldiers who nursed you, love you" (503) ${ }^{92}$.

$25 \mathrm{Au}$ vers 481, Stilicon est nommément désigné comme celui qui mène les opérations. Aux vers 488 sq. néanmoins, il s'agit bien d'Honorius, et de lui seul, et ce jusqu'au vers 504, car Claudien décrit des actes qui relèvent de la responsabilité de l'empereur : il loue alors des actions qui inscrivent Honorius dans la lignée de Trajan et qui reprennent ce que prônait Théodose (respect du Sénat, iustitia, pietas, maîtrise des passions). C'est que l'on passe ici aux praxeis en temps de paix : pour ce qui concerne les praxeis en temps de guerre, quel autre choix que de louer Stilicon? Toutefois, comme le note $\mathrm{C}$. Ware, ce que nous dit le poète semble bien plutôt s'appliquer au général ${ }^{93}$. D'ailleurs, Claudien ne manque pas, aux vers 502 (pro pignore) et 503 (te miles nutritor amat), de confiner Honorius dans son rôle d'enfant, et, à chaque fois, en parlant de sa relation avec l'armée: on pense alors à ce qu'il narrait dans le Panégyrique pour le troisième consulat d'Honorius, et nous voilà renvoyés derechef à la petite enfance de l'Empereur. C'est l'aura d'Honorius, et non son mérite, qui lui vaut cette affection. À partir du vers 518 , ce sont ses qualités physiques qui sont louées : l'éloge de ses praxeis effectives $^{94}$ aura été bien bref, et, même si en l'occurrence il est présenté comme agissant comme il le faut, Claudien continue de mettre en lumière le fait qu'il est toujours enfant et en apprentissage: Iam patrias imples galeas; iam cornus auita/ temptatur uibranda tibi ; promittitur ingens / dextra rudimentis Romanaque uota moratur ${ }^{95}$ et Cum uectaris equo simulacraque Martia ludis ${ }^{96} .$. Ce qu'il représente avant toute chose, c'est une image: une image de son père, au travers de sa ressemblance physique ${ }^{97}$ (v. 518-51998), une image de guerrier (v. 520 sq.9 ), une image de cavalier (v. 539 sq., avec simulacraque à la coupe au v. $539^{100}$ ). Il multiplie les références mythologiques pour exalter une matière qui serait sans cela bien pauvre. Lorsqu'il décrit le processus consularis de 398, on songe en arrière-plan à l'aduentus qui avait suivi la bataille du Frigidus, plusieurs années plus tôt ${ }^{101}$. Une fois que Claudien a énoncé quel programme politique Honorius devait suivre, les réalités qu'il loue ne sauraient donc avoir valeur de réalisations. À partir du vers 578 toutefois, il fait mention d'actions initiées par Honorius dans la lignée de la politique menée par son père. Le rejet de uel tu uel genitor ${ }^{102}$ est important, en ce qu'il souligne la continuité entre les deux. Mais le passage 
est bien bref, et il semble être là davantage pour contenter les sénateurs dont il est question que pour entériner une véritable prise de position de la part du Prince. Enfin, les vers $620 \mathrm{sq}$. font plusieurs fois mention des auspices d'Honorius, mais ceux-là viennent en réalité remplacer ses actions.

Pourtant, on l'a dit, Honorius est dorénavant en âge de régner, ou peu s'en faut : si Stilicon ne peut légitimement plus revendiquer auprès de lui une place de régent (si tant est qu'une telle place ait jamais été légitime, voir ci-dessus), il peut toujours revendiquer une place de père. Intégrer Stilicon dans la lignée familiale et lui donner la place de père, c'est aussi confiner Honorius dans son rôle d'enfant : certes, ce mariage consacre le passage du Prince à l'âge adulte, mais Claudien fait tout son possible pour le maintenir sous la tutelle de son beau-père et permettre au régent de conserver son autorité ${ }^{103}$. Contrairement à ce que semble dire l'empressement du futur époux (v. 20 sq.), c'est bien Stilicon qui en a fait avancer la célébration : alors que sa position était menacée, marier sa propre fille à l'Empereur était évidemment un moyen de conserver sur lui une certaine influence ${ }^{104}$. C'est dans ce contexte qu'il faut comprendre la place accordée à Stilicon dans les poèmes nuptiaux en l'honneur du mariage d'Honorius, qui est, de façon surprenante, prépondérante ${ }^{105}$.

\section{Les poèmes nuptiaux ${ }^{106}$ : Stilicon, nouveau Théodose?}

Ce qui est esquissé dans les poèmes précédents devient patent : Stilicon est un nouveau Théodose. Tout est fait dans l'Épithalame pour les noces de l'empereur Honorius pour mettre en valeur les liens familiaux qui unissent tous les protagonistes (Théodose comes, Théodose, Stilicon, Sérène, Honorius, Marie), et le monologue intérieur des vers 20-46 confirme que cette représentation a été parfaitement intégrée par Honorius. C'est ce que montrent le polyptote princeps/principe du vers 35 et la multiplication des termes désignant les liens familiaux, au point qu'il puisse être compliqué de suivre exactement le sens du propos (Claudien, Épithalame pour les noces de l'empereur Honorius 34-44) :

[...] Fateor, Stilicho, non parua poposci,

sed certe mereor princeps hoc principe natus,

qui sibi te generum fraterna prole reuinxit,

cui Mariam debes. Faenus mihi solue paternum,

redde suos aulae. Mater fortasse rogari

mollior. O patrui germen, cui nominis heres

successi, sublime decus torrentis Hiberi,

stirpe soror, pietate parens, tibi creditus infans

inque tuo creui gremio, partuque remoto

tu potius Flaccilla mihi. Quid diuidis ergo

pignora? Quid iuueni natam non reddis alumno"?

«Je l'avoue, Stilicon, ce que j'ai réclamé n'est pas négligeable, mais assurément je le mérite, prince né du prince qui s'est attaché ta personne en te faisant son gendre par la fille de son frère, à qui tu dois Marie. Paie-moi la dette contractée auprès de mon père, et rends à la cour les siens. Sa mère est peut-être plus facile à fléchir. ô fille de l'oncle du nom duquel j'ai hérité, gloire suprême de l'Èbre torrentueux, sœur par la souche, mère par l'affection, je te fus confié enfant, c'est sur ton sein que j'ai grandi, et, excepté la naissance, c'est toi davantage qui as été pour moi Flaccille. Pourquoi donc séparer tes enfants? Pourquoi ne pas rendre ta fille à celui que tu as nourri dans son jeune âge? »

En outre, Claudien ne recrée pas la lignée impériale en amont seulement : il décrit la future descendance d'Honorius, évidemment porphyrogénète elle aussi, aux 
vers 259-261: Accipe fortunam generis, diadema resume, / quod tribuas natis, et in haec penetralia rursus, / unde parens progressa, redi ${ }^{107}$. Ce n'est pas seulement affirmer une évidence ici : c'est confirmer que le pouvoir appartient désormais à cette famille - de laquelle Stilicon fait indubitablement partie. Cette place lui est accordée par sa valeur : alors qu'Honorius aidait son père à obtenir la victoire quand la bataille était placée sous ses auspices (pugnastis uterque, Panégyrique pour le troisième consulat d'Honorius 88), Stilicon réalise de façon effective ce qui n'est qu'en germe chez le Prince. C'est ce qu'expriment l'expression socio Stilichone au vers 220 et l'éloge de Stilicon par l'armée aux vers 300-341 - éloge placé sous l'autorité de Théodose divinisé108. Cet éloge fait par les soldats ne se limite pourtant pas à ses seuls talents militaires, rapidement évacués dans la prétérition des vers 309-312 (Dicere possemus, quae proelia gesta sub Haemo/ quaeque cruentarint fumantem Strymona pugnae, / quam notus clipeo, quanta ui fulminet hostem, / ni prohiberet Hymen ${ }^{109}$ ). Les « rênes » du pouvoir que son père avaient confiées à Honorius dans le panégyrique pour son troisième consulat sont ici dans les mains de Stilicon (v. 308) ${ }^{110}$, en vertu de sa sagesse, de son sens du droit et du juste, de son courage, de son égalité d'âme, de sa noblesse d'esprit jointe à sa ciuilitas, de son invulnérabilité à la corruption : tout le passage est un condensé du miroir des princes du Panégyrique pour le quatrième consulat d'Honorius, appliqué cette fois à Stilicon. J.-L. Charlet souligne que Stilicon est doté d'une image impériale, et qu'il se voit même placé au-dessus d'Honorius ${ }^{111}$. Inuictus (inuicte, v. 336) est une épithète d'empereur, et Claudien accumule en trois vers autant de superlatifs que possible: Ipse metus te noster amat, iustissime legum / arbiter, egregiae pacis fidissime custos, / optime ductorum, fortunatissime patrum ${ }^{112}$ - ce dernier superlatif rappelant en outre l'apostrophe adressée à Théodose fortunate parens au vers $178 \mathrm{du}$ Panégyrique pour le troisième consulat d'Honorius. Le vers 334 réunit d'ailleurs la double fonction, de chef et de père, qui définissait Théodose lorsqu'il confiait à Stilicon la protection de ses fils, sans que l'on précise ici pour qui Stilicon est un père: pour Marie, ou pour Honorius? Les vers suivants définissent sa descendance, mais ce ne sont pas seulement Marie, Eucherius et Thermantia. La descendance espérée pour Honorius apparaît mise en parallèle avec les enfants de Stilicon, et quand il s'agit d'Eucherius, le vers 338 reproduit exactement ce que dit le poète d'Honorius: Sic puer Eucherius superet uirtute parentem ${ }^{113}$. Enfin, le dernier vers met Stilicon à la place de Théodose avec auitis, le dernier mot du poème, qui jusqu'à présent n'était utilisé que pour désigner Théodose comes, le grand-père de la famille ${ }^{114}$. Après avoir récapitulé ses qualités d'homme d'État, Claudien fait maintenant de Stilicon un membre de la famille impériale à part entière, ancêtre de ses enfants nés dans la pourpre et destinés au pouvoir par leur naissance - Honorius, Marie, et leur futur fils. Le troisième poème des Fescennins accentue encore la portée politique de ces pièces nuptiales. Pour J.-L. Charlet, l'apostrophe à Stilicon assure l'équilibre entre les pièces panégyriques et les pièces lyriques ${ }^{115}$. Mais elle est aussi le moyen de confondre à nouveau Stilicon et Théodose ${ }^{116}$, à travers le jeu entre les appellations pater, socer et gener. Cette association sera encore confirmée dans La Guerre contre Gildon: Stilicon, socer au vers 352, devient sancte pater dans la bouche d'Honorius au vers 354. De même, au livre 2 du Consulat de Stilicon (v. 66-73), l'enseignement que Stilicon donne à Honorius est présenté comme la continuité de celui prodigué par Théodose (l'enseignement « à la dure " allié à la volonté de ne pas briser les élans du jeune élève comme dans le Panégyrique pour le troisième consulat d'Honorius), et Stilicon lui-même est à la fois dux et parens, ce qui reprend les termes patriis et dominum qui se rapportent à Théodose ${ }^{117}$. Un peu plus loin, dans l'ekphrasis qui décrit la trabée que doit revêtir Stilicon, l'auus qui va 
instruire le fils d'Honorius et de Marie est bien Stilicon, comme Théodose l'a fait en son temps pour Honorius (v. 348) ${ }^{118}$. Aux vers 357 et 361, Claudien use des figures du polyptote, du chiasme et du parallélisme pour figurer le mélange intime des deux lignées, celle de Théodose et celle de Stilicon, dont l'union est consacrée par l'usage du singulier domus haec au vers 360 - reginasque parit, qui renvoie à Marie, confirme bien en effet qu'il ne saurait s'agir ici que de la seule lignée théodosienne (Claudien, Le Consulat de Stilicon 2, 357-361):

Eucherius trepido iam flammea subleuat ore uirginis ; adridet retro Thermantia fratri.

Iam domus haec utroque petit diademata sexu

reginasque parit reginarumque maritos.

«Voici qu'Eucherius soulève le voile du visage frémissant de la jeune vierge; le sourire de Thermantia répond à celui de son frère. Voici que cette maison réclame le diadème pour les deux sexes: elle engendre des reines et pour les reines des époux.»

\section{Hic est ille puer, qui nunc ad rostra Quirites / euocat ${ }^{119}$ : le Panégyrique pour le sixième consulat d'Honorius}

Mais au moment où Claudien récite le panégyrique pour son sixième consulat, Honorius a vingt ans, il a donc largement l'âge d'assumer le pouvoir : le poète doit faire évoluer les rôles qu'il construit poème après poème pour son Empereur et pour Stilicon. Sa visée principale va être ainsi de définir la figure du Prince dans la lignée du princeps occidental (et même plus : romain) des premiers temps de l'Empire, et pour cela la présence des figures impériales au sein du poème va se faire plus complexe, tandis que la représentation des relations du Prince et de Stilicon va être amenée à se transformer. En outre, ce panégyrique a été écrit pour la visite d'Honorius à Rome en 404, ce qui n'est pas sans conséquence ${ }^{120}$.

La première figure impériale qui apparaitt est Théodose, au vers 55, lorsque Claudien s'apprête à célébrer l'enfance d'Honorius, comme il est normal de le faire au début d'un panégyrique. Est inauguré ici un long passage marqué par la présence du père de l'Empereur, jusqu'au récit de la défaite d'Alaric qui commence au vers 127. Il est présent à deux titres : d'une part parce qu'il a guidé son fils sur la voie des antiques vertus civiques, et d'autre part parce qu'il est celui qui assure la légitimité première d'Honorius, celle du sang. Honorius n'est toutefois plus cantonné à ce seul moment de son existence qu'est son enfance : son aduentus présent est le miroir de l'aduentus passé de 389 , mais entre-temps, il a grandi ${ }^{21}$. M. Dewar note que l'apostrophe princeps uenerande (v.53) qui introduit le rappel de sa première venue à Rome constitue un oxymore, parce que la révérence est normalement liée à l'âge ${ }^{122}$, et il établit un parallèle avec le uenerande puer de Nisus à Euryale dans l'Énéide ${ }^{123}$. Or, s'il y a allusion au puer uenerande, c'est pour souligner l'écart avec la situation présente : l'âge de sa prime jeunesse est relégué dans le passé (Haec sunt, quae primis olim miratus in annis / patre pio monstrante puer ${ }^{124}$ ). Le poète ne cherche plus à camoufler le fait qu'il est dorénavant tout à fait en âge de régner pour mettre en avant Stilicon. Ce qui était en germe quand Honorius était aux côtés de son père se voit aujourd'hui réalisé, et c'est bien la première fois qu'on lit une telle réalité chez Claudien ${ }^{125}$. Certes, dans quelques passages $^{126}$ du Panégyrique pour le quatrième consulat d'Honorius, Claudien attribuait des vertus au gouvernement d'Honorius, mais nous avons pu voir que sa responsabilité 
personnelle à ce sujet était loin d'être affirmée avec netteté. Ici, la circonstance même de la visite offerte à Rome apparaît comme l'acte fondateur d'une nouvelle politique qui ferait à nouveau de la cité romaine le cœur du pouvoir ${ }^{127}$, le pouvoir impérial étant conçu comme l'exercice au sens strict du Principat, dans la lignée de l'héritage de Théodose, optimus ille (v. 55), et des melioribus [...] / [...] exemplis (v. 58-59) du passé (c'est-à-dire ceux qui se sont comportés en principes et non en tyrans hautains et enfermés dans leur palais : se [...] / [...] ciuem gereret terrore remoto, v. 58-59). Claudien utilise donc la circonstance de la venue d'Honorius pour la transformer en méditation politique sur la place du Prince et sur le cœur de l'Empire qui poursuit celle qui apparaissait déjà dans ses poèmes politiques antérieurs. Il adapte néanmoins la représentation qu'il donne du pouvoir à l'époque qui est la sienne. Elle est marquée par une tension entre deux images, celle du princeps et celle du rex: à côté des vertus civiques sont énumérés les signes du pouvoir royal et du statut divin du prince - la tiare, le trône, les étrangers qui se prosternent devant lui. Mais c'est seulement dans un second temps que Claudien concède une telle représentation. Au cœur de celle-ci, il y a, outre la volonté probable de répondre aussi aux attentes des partisans d'un pouvoir à la mode orientale, la question de la double légitimité d'Honorius et de Stilicon. Le pouvoir se transmet désormais par le sang. C'est pourquoi Claudien ne fait pas l'économie d'un rappel du fait que Théodose est celui qui a transmis son pouvoir à son fils, qui l'a reçu à la naissance avant même de le mériter (v. 65 sq.), et que Stilicon fait partie de la famille du Prince. Le passage qui couvre les vers 88-100 est émaillé de termes se rapportant aux liens familiaux (patrio, materna, generumque, pignus, patrui, mariti, coniugis) qui se mêlent intimement avec le lexique politique (rectorem, sceptris, castrisque, pietate, fidaeque, officio), Stilicon et Sérène deviennent les parents d'Honorius, et à eux trois ils ne forment qu'une seule et même domus au vers 99 - le terme est mis en valeur à la coupe. Théodose n'est pas nommé, mais il est appelé seniore, terme qui jusque-là était employé pour parler de Théodose comes $^{128}$ : c'est qu'ici, avant d'être le personnage politique, il est l'ancêtre. De même, il est patre au vers 55, et parens au vers 101. L'accent est mis ici sur la dimension familiale de la transmission du pouvoir. L'adresse qui suit, aux vers 101-107, consacre cet héritage en cultivant la possibilité d'une confusion sur la personne du destinataire de l'adresse (Claudien, Panégyrique pour le sixième consulat d'Honorius 101-107):

Felix ille parens, qui te securus Olympum succedente petit ! Quam laetus ab aethere cernit

se factis creuisse tuis! Duo namque fuere

Europae Libyaeque hostes: Maurusius Atlas

Gildonis Furias, Alaricum barbara Peuce

nutrierat, qui saepe tuum spreuere profana

mente patrem [...].

« Heureux père, qui a gagné l'olympe serein de te savoir son successeur ! Quelle doit être sa joie de voir depuis le ciel tes exploits grandir sa gloire! L'Europe et la Libye se sont trouvées sous la menace de deux ennemis : l'Atlas africain avait donné le jour au féroce Gildon, et Peucé au barbare Alaric, et tous deux, sacrilèges, ont souvent méprisé ton père. "

31 La première lecture laisse à penser que celui-ci est Honorius, mais Stilicon est le dernier personnage mentionné. Ainsi, si à sa mort Théodose a laissé sa succession en toute sécurité (securus), est-ce parce qu'il l'a laissée à Honorius sous la protection du grand Stilicon, ou bien parce qu'il l'a laissée au général vandale? Peut-on vraiment penser que les factis [...] tuis sont ceux d'Honorius, qui ne s'est pas encore illustré, et 
alors même que creuisse est au passé ? Tuum [...] / [...] patrem aux vers 106-107 peut sembler lever l'équivoque ${ }^{129}$, mais Théodose n'est-il pas devenu en quelque sorte le père de Stilicon depuis son mariage avec sa fille adoptive, surtout si Honorius est devenu son fils ${ }^{130}$ ? Toutefois, ce qui suit nous offre une représentation inédite des relations unissant Honorius, son père et Stilicon. Certes, le récit de la lutte contre Alaric depuis Pollentia jusqu'à Vérone est centré sur ce dernier personnage, protagoniste des événements (voir par ex. le v. 210, mais aussi les paroles d'Alaric), et Honorius est évacué. Mais à l'ouverture du récit, la victoire est décrite comme étant celle $\mathrm{d}^{\prime}$ Honorius ${ }^{131}$. Claudien insiste plusieurs fois sur le fait que celui-ci agit en vengeur de son père. Une double comparaison permet d'exalter son action. L'exemple mythologique, avec Oreste, et l'exemple historique, avec Auguste, disent que celle-ci relève tout à la fois de ce qu'exige la pietas due à son père ${ }^{132}$ et de la politique. Or Honorius surpasse le Princeps fondateur de l'Empire, car la guerre qu'il a remportée est une guerre étrangère, et non une guerre civile ${ }^{133}$, et en même temps, il surpasse son propre père. En guise de conclusion au récit guerrier, Claudien affirme qu'Honorius dépasse même Stilicon : Acrior interea uisendi Principis ardor / accendit cum plebe Patres ${ }^{134}$. L'éloge de Stilicon cède le pas à l'affirmation franche du rôle d'empereur d'Honorius. Théodose réapparait lors de la description du triomphe d'Honorius. C'est l'occasion de peindre Stilicon aux côtés de l'Empereur et de rappeler le testament de son père. Il est d'ailleurs notable que, cette fois-ci, le poète parle d'une régence exercée au nom d'Honorius seul (illumque diem sub corde referres, / quo tibi confusa dubiis formidine rebus / infantem genitor moriens commisit alendum ${ }^{135}$ ) : parce qu'il a grandi, et parce que Stilicon a désormais renoncé à toute tutelle sur l'Orient ${ }^{136}$, Claudien doit inciter Honorius à se positionner clairement en face du roi oriental qu'est son frère Arcadius. Ce moment constitue le couronnement de l'action du régent, mais celle-ci est reléguée dans le passé, tout comme l'est l'âge d'enfant du Prince. Il a effectué son service, il en reçoit la récompense ${ }^{137}$. Ce qui est rapporté au présent, c'est Honorius qui exerce son office. Le poète délimite un peu plus ce que doit être l'action politique du Prince : elle doit suivre l'action de Stilicon, dépositaire de l'héritage de Théodose, main armée d'Honorius, architecte de ses victoires, et presque son égal dans les triomphes - à ceci près qu'il n'est pas le Prince lui-même ${ }^{138}$. On a donc une évolution de la relation entre Honorius et Stilicon autour de la question du pouvoir : dans le Panégyrique pour le troisième consulat d'Honorius, on insiste sur le fait que Stilicon gouverne à la place d'Honorius (le pouvoir lui a été confié jusqu'à ce qu'il doive le rendre), alors que dans ce panégyrique-ci Honorius et Stilicon se complètent ${ }^{139}$.

Par ailleurs, dans ce panégyrique, outre Théodose, les figures impériales se multiplient autour d'Honorius. Jusqu'à présent, elles n'avaient pas la même fonction selon qu'elles accompagnaient Honorius ou Stilicon. Théodose était essentiellement invoqué pour légitimer Stilicon, et lorsque ce dernier était comparé à Trajan, c'était pour être surpassé ; en ce qui concerne Honorius, il était représenté comme l'enfant de Théodose devant être éduqué, à qui était présenté notamment le règne de Trajan comme but à atteindre. Or ici, Honorius, qui vient d'être décrit comme supérieur à Théodose, est présenté comme supérieur à Trajan et à Marc Aurèle (Claudien, Panégyrique pour le sixième consulat d'Honorius 333-341) :

[...] nec tali publica uota

consensu tradunt ataui caluisse per urbem,

Dacica bellipotens cum fregerat Ulpius arma

atque indignantes in iura redegerat Arctos, 
cum fasces cinxere Hypanin mirataque leges

Romanum stupuit Maeotia terra tribunal.

Nec tantis patriae studiis ad templa uocatus,

clemens Marce, redis, cum gentibus undique cinctam

exuit Hesperiam paribus Fortuna periclis.

«[...] et nos aïeux racontent que les vœux du peuple à travers la ville n'étaient pas aussi ardents et unanimes quand le puissant guerrier Ulpius revint après avoir écrasé les Daces et soumis à nos règles les peuples de l'Ourse qui s'étaient révoltés, quand les faisceaux eurent bordé les rives de l'Hypanis et que la terre de Méotie eut découvert avec stupeur les lois et le tribunal de Rome. Et il n'y eut pas un empressement aussi grand, Marc Aurèle, quand, de retour dans ta patrie, tu revins dans ses temples remercier la Fortune pour avoir délivré de dangers semblables l'Hespérie cernée de tous côtés par les Barbares. »

Alors que jusqu'à présent Trajan était l'optimus, on a ici une gradation de Trajan à Marc Aurèle: le premier n'a pour lui que ses victoires militaires et l'extension de son territoire qu'il a offerte à Rome, tandis que l'épithète clemens du second montre que ce n'est pas à sa seule dimension guerrière que pense Claudien. Les vers 349-350 le confirment, dans l'hypothèse envisagée comme la plus juste pour expliquer sa victoire et appuyée par l'engagement personnel du poète (quod reor) : Claudien parle du mérite dû à sa vertu. On a donc ici un déplacement de la clementia, de Trajan vers Marc Aurèlle $^{140}$. Il est remarquable de voir que Trajan est réduit à ses conquêtes, lui qui était l'empereur mitis par excellence, alors que c'est le second qui est qualifié de clemens. On pense au passage du Consulat de Stilicon où Claudien dit de Stilicon qu'il surpasse Trajan (Cedant, Druse, tui, cedant, Traiane, labores $\left.{ }^{141}\right)$ : contrairement à ce qui se passe pour Honorius dans le panégyrique pour son quatrième consulat, Trajan n'y est pas convoqué pour établir une lignée, mais c'est un faire-valoir destiné à confirmer la légitimité de Stilicon à la tête de l'État. J.-L. Charlet note toutefois que la synkrisis est ici seulement rhétorique car, finalement, ce n'est que par ses exploits guerriers qu'il le fait, alors que dans le Panégyrique pour le quatrième consulat d'Honorius cet aspect-là était secondaire, car moins important en dignité que sa clementia $^{142}$. Or, dans ce texte, Honorius surpasse Trajan par quelque chose de plus que Stilicon ${ }^{143}$. Le vers 355 résume tout ce qui précède en ce qui concerne les rôles d'Honorius et de Stilicon, et constitue une correction par rapport à tous les poèmes antérieurs : pour la première fois, Stilicon est au second plan, et c'est bien la uirtus d'Honorius qui est affirmée. Ce qui apparaît donc, c'est que ce n'est plus l'homme Trajan qui est important, dans une dimension dynastique et courtisane, mais bien la vertu du prince idéal à présenter à Honorius comme objectif à atteindre. La revendication généalogique cède le pas à la démonstration pour le jeune Prince de l'idéal vers lequel il doit tendre dans l'exercice de son pouvoir. Ce n'est pas la première occurrence d'un effacement de la figure de Trajan : lorsqu'au tout début du panégyrique Claudien célèbre la ciuilitas du Prince, on s'attendrait à ce qu'il soit mentionné : J.-L. Charlet note le parallèle possible entre les vers 5-7 et 10 et le $\S 63$ du panégyrique de Pline. De même, lorsque dans sa prosopopée Rome va énumérer des noms de grands empereurs, Trajan ne sera pas non plus nommé. Comme l'analyse J.-L. Charlet, c'est un moyen de dépasser le culte de la personnalité : Trajan n'est plus l'horizon indépassable, le modèle achevé du bon empereur. C'est à Honorius qu'est confié le soin de le devenir, et pour cela, il faut le circonscrire dans un ensemble de références politiques qui doivent lui servir de modèles. Ici, l'accent est donc mis sur la clémence ${ }^{144}$ : par ce choix, Claudien évoque aussi le prince idéal défini par Sénèque dans le De clementia. Ailleurs, ce sont d'autres vertus nécessaires qui sont soulignées: Théodose se faisant accompagner de son jeune fils lors de son séjour à 
Rome est qualifié de pius ; quand il réapparaît à la toute fin du poème, il est bellipotens. À son tour, il n'est pas là tant pour expliquer la légitimité de la présence d'Honorius sur le trône que pour servir de modèle appelé à être dépassé. En plus d'incarner les vertus qui sont celles du bon empereur, Honorius est aussi celui grâce à qui le pouvoir impérial va s'incarner de nouveau dans Rome. La mention de la déesse Fortuna qui accompagne le nom de Marc Aurèle rappelle le premier vers du poème, où Fortuna Redux est célébrée par les priores (Claudien, Panégyrique pour le sixième consulat d'Honorius 1-5) :

Aurea Fortunae Reduci si templa priores

ob reditum uouere ducum, non dignius umquam

haec dea pro meritis amplas sibi posceret aedes,

quam sua cum pariter trabeis reparatur et urbi

maiestas [...].

«Si nos ancêtres consacraient des temples ornés d'or à Fortuna Redux en l'honneur du retour de leurs généraux, jamais cette déesse ne serait plus en droit de réclamer pour son aide un monument magnifique que quand la trabée retrouve son éclat et la Cité sa majesté.»

Or, comme le souligne M.-F. Guipponi-Gineste dans son article sur le retour d'Honorius à Rome dans le panégyrique pour son sixième consulat, cela fait référence à l'édification par Auguste en 19, lors de son retour d'Orient, d'un autel en l'honneur de la déesse ${ }^{145}$ : "Sur le plan religieux et politique, en ouvrant le panégyrique sur la divinité Fortuna Redux, le poète place l'aduentus triomphal et le consulat dans leur contexte républicain et augustéen ${ }^{146} »$. Ainsi les références qui permettent à Claudien de construire le modèle du prince offert à Honorius s'incarne concrètement dans l'espace romain : il ne fait pas que mentionner des grands noms d'empereurs, il relie leur règne à son inscription profonde dans la ville de Rome.

Est-ce à dire qu'il est enfin parvenu au but? Certes, il surpasse ces grands noms, mais seulement par l'attente que les Romains ont de lui, dans leur appel à l'union entre le Prince et Rome, autrement dit par l'attente d'une prise de position politique de sa part : l'enjeu du panégyrique est de conduire le Prince à ressembler à l'image que l'on attend de lui. Le récit de la défaite d'Alaric nous amène justement à l'expression par la prosopopée du désir de Rome de voir l'aduentus du Prince pour en célébrer le triomphe, qui se voit donc exprimé tant par le poète que par la voix de Rome elle-même. La prématurité des désirs de son fils que Théodose lui opposait pour l'engager à attendre est remplacée par l'urgence dans l'annonce de la prosopopée de Rome. C'est qu'à l'âge qu'atteint l'Empereur il n'est précisément plus temps d'attendre: il faut affirmer devant les auditeurs qui vont entendre le panégyrique qu'Honorius est prêt à assumer sa fonction. Dans les vers 361 sq., Claudien récrit la prosopopée de Respublica dans le Panégyrique de Théodose $e^{147}$, en transformant le motif de la recusatio imperii en refus supposé de la part d'Honorius d'honorer Rome de sa présence ${ }^{148}$ : c'est dire l'étroite relation qui existe pour Claudien entre le fait de bien régner et le fait de régner à Rome $^{149}$. C'est bien un geste d'affirmation politique qu'elle sollicite de l'Empereur : son aduentus à Rome.

Comme Pacatus, qui mentionne Nerua tranquillus, amor generis humani Titus, pietate memorabilis Antoninus, cum moribus Augustus ornaret, legibus Hadrianus imbueret, finibus Traianus augeret ${ }^{150}$, Claudien cite des noms d'optimi principes ${ }^{151}$, Nerva, Antonin, les Sévères (Claudien, Panégyrique pour le sixième consulat d'Honorius 413-421) :

Segnius an ueteres Histrum Rhenumque tenebant,

qui nostram coluere domum? Leuiusue timebant

Tigris et Euphrates, cum foedera Medus et Indus 
hinc peteret pacemque mea speraret ab arce?

Hic illi mansere uiri, quos mutua uirtus

legit et in nomen Romanis rebus adoptans

iudicio pulchram seriem, non sanguine duxit ;

hic proles atauum deducens Aelia Neruam

tranquillique Pii bellatoresque Seueri.

«Les princes qui habitaient cette demeure autrefois se sont-ils montrés plus nonchalants à contenir l'Ister et le Rhin ? Le Tigre et l'Euphrate tremblaient-ils plus doucement quand le Mède et l'Indien venaient ici solliciter une alliance ou quand ils espéraient obtenir la paix de la part de ces murs? C'est ici que demeuraient ces hommes qui se désignaient l'un l'autre pour leur valeur et qui, se transmettant leur nom par l'adoption pour le gouvernement de Rome, ont créé une noble lignée fondée non pas sur le sang, mais sur le discernement. C'est ici qu'a vécu la postérité Élienne qui remontait à Nerva, les pacifiques Pii, les belliqueux Sévères. »

Si Pacatus cite tous ces noms, c'est pour montrer que Théodose a été le premier à recevoir l'Empire malgré lui, et sans le devoir «ni à la brigue, ni à l'occasion, ni à la parenté " $(12,1)$. On trouvait déjà un écho à cette idée dans le Panégyrique pour le quatrième consulat d'Honorius (v. 45 sq.). Mais Claudien ne dit pas exactement la même chose ici. Il s'efforce de dépasser la synkrisis encomiastique et le topos de la surenchère pour mettre en lumière, avant toute chose, les qualités du bon prince. Sans les nommer, il parle aussi des ueteres [...] qui nostram coluere domum et des uiri quos mutua uirtus / legit. C'est mettre l'accent à la fois sur l'attachement intrinsèque de la figure impériale avec la ville de Rome ${ }^{152}$ et sur le choix du meilleur, sans incarner ces deux valeurs dans des figures particulières : nous retrouvons le processus de détachement de la figure idéale des individus susceptibles de l'incarner. Dans les vers qui suivent, les noms qu'il donne renvoient aux qualités attribuées ailleurs dans le poème à la figure impériale : la piété d'Antonin et de ses successeurs ${ }^{153}$, qui est aussi celle de Théodose, le talent militaire des Sévères, qui est aussi celui de Théodose et de Trajan. Nerva, lui, est présent au titre de fondateur d'une lignée établie sur l'adoption. Le terme de ciuis renvoie à la ciuilitas de Théodose illustrée lors de sa venue en 389 - vertu également incarnée par Trajan ailleurs. Antonin incarne encore la tranquillitas, qui est aussi la vertu associée à Nerva et à Marc Aurèle. Même si Hadrien n'est pas nommé, Aelius est son nomen gentile. Les pluriels Pii et Seueri ajoutent dans la liste les descendants d'Antonin et de Septime Sévère. Les grands noms semblent passer au second plan, après les vertus que Claudien voudrait voir incarner par Honorius. Il faut toutefois expliquer les noms qu'il choisit de donner. On remarque qu'il ne mentionne que des empereurs postérieurs à Nerva, alors que l'exemple de Pacatus nous montre que Titus aurait pu servir lui aussi de modèle. Autrement dit, la liste des bons empereurs s'ouvre là où commence l'intérêt généalogique pour Honorius. En outre, il fait le choix de nommer les Sévères, là où l'on attendrait qu'il nomme Trajan (c'est leur activité guerrière qui les associe). F. Chausson montre l'intérêt généalogique qu'il y a à regrouper sous le même nom des Aelii les Antonins et les Sévères :

Cet éloge de la proles Aelia (dont il est abusif stricto sensu de dire qu'elle remonte à Nerva, puisqu'elle tire son nom d'Hadrien) n'est sûrement pas anodin: le père d'Honorius, Théodose, prétendait descendre des Antonins; quant à la mère d'Honorius, elle se nommait Aelia Flauia Flaccilla et était elle aussi d'origine espagnole. Il est bien possible que le nom de la mère d'Honorius ait suscité une telle mention de la famille Aelia. Claudien aurait ainsi multiplié les allusions à la généalogie du prince, d'une manière très subtile qui ne laissait cependant d'être transparente pour un public bien au fait de ce que disaient d'autres panégyriques et la propagande même de la Maison impériale ${ }^{154}$. 
Avec Septime Sévère, en outre, la transmission du pouvoir se fait ouvertement héréditaire, lui-même se rattachant aux Antonins, et associant ses deux fils à son pouvoir. Ainsi Claudien maintient un équilibre extrêmement subtil entre l'idée de la vertu, des grands modèles, de la succession par le sang, et de la succession par l'adoption. C'est que l'adoption elle-même n'est pas un gage d'assurance au sujet des qualités du successeur : $\mathrm{M}$. Dewar rappelle que toute une tradition hostile à Hadrien a accusé Trajan d'avoir fait un choix aussi mauvais que celui d'Auguste ${ }^{155}$. Nous avons dit aussi au sujet de l'accession au pouvoir de Trajan qu'elle n'a même pas été en son temps un gage de légitimité. Il semblerait finalement que la meilleure situation soit celle où l'on puisse allier choix de l'empereur en place, légitimité par le sang, et mérite personnel du successeur. Si Honorius se montre à la hauteur, ce sera précisément son cas : Théodose aura fait de son fils par le sang son successeur par la vertu. Il faut dire que si ni Nerva, ni Trajan, ni Hadrien, ni Antonin n'ont eu de fils, les Antonins sont liés d'une manière ou d'une autre par le sang, et que si le choix du meilleur a été fait, c'est dans le cercle de la famille ${ }^{156}$. L'idée de transmission familiale du pouvoir n'est donc pas complétement évacuée par Claudien, et ce, même en dehors de la seule adoption qui, en permettant de choisir de qui on fait son fils, permet de créer un lien familial basé en réalité sur la cooptation. Ainsi, tout en déniant la valeur du sang (legit en rejet au vers 418, qui encadre le vers avec adoptans, iudicio [...] non sanguine), et bien qu'il occulte complètement les empereurs du $\mathrm{IV}^{\mathrm{e}}$ siècle qui n'ont dû leur règne qu'à la transmission dynastique ${ }^{157}$, il n'a de cesse de parler de la lignée des empereurs ${ }^{158}$. Il est indéniable que celle-ci ne saurait garantir seule la qualité de celui qui possède le trône. Mais si sa méfiance envers la transmission dynastique est tout à fait réelle, on ne peut pas dire non plus qu'il la refuse. Bien plus, il admet tout à fait la possibilité de l'alliance entre celle-ci et la vertu. Claudien a pris acte de l'évolution du régime impérial depuis le $\mathrm{I}^{\text {er }}$ siècle. La fin de la prosopopée de Rome entérine cette réalité : autour d'Honorius gravitent les figures de son père, patris, et de son beau-père, socero.

Dans l'utilisation qu'il fait des noms des optimi principes dans ce panégyrique, Claudien semble reproduire ici le mouvement que l'on observe dans le discours officiel sous Théodose et qu'a décrit $\mathrm{F}$. Chausson ${ }^{159}$ : la progressive mise au second plan de Trajan au profit des bons empereurs parmi ceux qui lui ont succédé. Mais il le traite, au moins en partie, à rebours. Pour Théodose, cet effacement visait à mettre en avant un modèle de transmission dynastique du pouvoir. Pour J.-L. Charlet, Claudien accentue au contraire ici l'idée du mérite. En réalité, lien familial et cooptation semblent définitivement aller de pair dans la représentation qu'il donne du bon pouvoir impérial. Claudien condense en ces quelques vers toute l'évolution du discours officiel théodosien, depuis l'idée du choix du meilleur jusqu'à la continuité dynastique, en faisant d'Honorius l'homme capable de réunir ces deux idées que l'on pouvait penser contradictoires. Il ne vise pas le culte de la personnalité, mais la construction de la figure du bon empereur. Le gouvernement à la manière de Trajan prend une place absolument capitale ici, comme c'était le cas dans le panégyrique impérial précédent, mais l'homme Trajan s'efface : on passe de la personne à la fonction. Même sa fonction d'ancêtre fondateur de la lignée passe au second plan. Théodose aussi s'efface, qui n'a plus la parole. Dans les panégyriques précédents, la leçon de politique visait davantage à légitimer le pouvoir de Stilicon en montrant l'adéquation entre le modèle et Stilicon, et l'inadéquation entre le modèle et Honorius : il fallait justifier qu'un enfant règne, mais tout en laissant le gouvernement effectif au régent. Ici, Claudien crée une figure du prince idéal, et, tout 
en affirmant la perfection de Stilicon, il affirme la possibilité d'y parvenir pour Honorius, qui doit se démarquer d'Arcadius qui a fait le choix d'être un roi oriental.

Et en effet, cette fois, il n'est plus autant question qu'avant de mettre en exergue la faiblesse d'Honorius par rapport à ce que l'on attend de lui. Avant même que Rome ne passe en revue les exemples du passé, elle affirme qu'il est homme de vertu et de mérite, et répète ce que nous disait déjà le poète, à savoir que le triomphe à venir est bien le sien, et non celui de Stilicon (v. 386-388). La réponse du Prince remplit enfin les attentes de la cité, et juste après celle-ci, Claudien nous relate sa mise en route depuis Ravenne en direction de Rome. Pour la première fois, personne ne vient l'empêcher d'agir après qu'il a répondu à la leçon qu'on lui donne. Engagé par le discours que Claudien lui a fait prononcer, il est sommé d'agir, alors que les panégyriques précédents visaient plutôt à justifier sa mise en retrait. Maintenant, Claudien peut louer Honorius, car ce n'est plus tant le vrai Honorius qu'il loue que la fonction qu'il incarne - ou plutôt, qu'il veut qu'il incarne : il surimpose sur le personnage, qui n'a pas encore fait ses preuves, sa propre vision. Il n'est plus le chantre de Stilicon, ni même tellement d'Honorius, mais du pouvoir impérial inscrit dans Rome.

On voit bien ce que ce poème a de polémique, dans le sens où il ménage au sein du propos encomiastique et officiel un espace pour un propos plus personnel de Claudien. Le panégyrique ne fonctionne pas comme celui de Pline. Dans sa contribution à l'ouvrage The Propaganda of Power. The Role of Panegyric in Late Antiquity ${ }^{160}$, S. M. Braund rappelle la difficulté qui se pose à lui au moment de louer les exploits de son empereur alors qu'il écrit au tout début de son règne (Trajan accède à la magistrature suprême en 98 , Pline prononce son panégyrique devant le Sénat en 100). L'éloge, au-delà de la simple louange, peut ainsi se faire programmatique : « it can reflect or even prescribe a program of behaviour to the new emperor ${ }^{161} »$. Entre cette fonction de prescription et le grand tact que l'orateur doit nécessairement conserver quand il décrit la figure de l'empereur, se dessine alors pour le premier un rôle de conseiller qui se rapproche de celui qu'un Sénèque pouvait tenir auprès du jeune Néron. Mais quand Pline affirme que, malgré sa jeunesse dans sa fonction, Trajan est déjà une figure achevée de la perfection et qu'il ne lui manque donc plus que de la réaliser par ses actions politiques, Claudien ne le dit pas au sujet d'Honorius, qui est pourtant légalement en mesure d'exercer le pouvoir depuis de nombreuses années déjà ${ }^{162}$. Or c'est dans cette situation particulière qu'apparaît pleinement le fonctionnement à double détente du panégyrique, qui permet de concilier éloge et liberté de parole. Le choix du panégyrique pour tenir un discours polémique est en effet surprenant à première vue. Mais il permet un effet de sens intéressant, que décrit notamment B. Bureau dans son article «Irrévérence de la révérence et révérence de l'irrévérence : le Contre Eutrope et le Panégyrique pour le sixième consulat d'Honorius de Claudien ${ }^{163}$ " : le panégyrique peut aller au-delà du simple éloge et se transformer en contrat moral conclu entre l'encomiaste et son sujet, et dont l'auditoire, en sa qualité de témoin, sera aussi le juge de sa concrétisation dans les faits. Au lieu de dire « je te loue parce que », le premier dit au second "tu mérites d'être loué si », et il le contraint donc à suivre le programme qu'il lui prescrit. Pour cela, il le circonscrit dans un ensemble de valeurs et superpose sa fonction avec d'autres figures impériales, Auguste, Nerva, Trajan, Hadrien, Marc Aurèle, Antonin, Septime Sévère, Théodose. D'ailleurs, dans ce panégyrique, la manière dont il interpelle le prince diffère par rapport aux panégyriques précédents ${ }^{164}$ : les apostrophes le circonscrivent dans un type de gouvernement, dans la lignée du Principat. Il est appelé princeps uenerande (v. 53), princeps (v. 354 et 632) et Auguste 
(v. 657-660): c'est sa fonction que l'on souligne. On remarque l'insistance sur l'appellation princeps, utilisée trois fois : Claudien replace le pouvoir d'Honorius dans sa lignée civique, et impose une représentation de l'Empereur en tant que ciuis. Les apostrophes qu'il choisit d'employer pour interpeller le Prince n'ont pas seulement une fonction phatique ${ }^{165}$ : elles ont une vraie fonction d'appel et de définition de la personne interpellée, et elles deviennent performatives ${ }^{166}$ en ce qu'elles lui imposent cette définition. Claudien essaie de lui imposer un discours qui va au-delà des attentes du genre : il s'emploie à le mettre sur la voie de la figure politique idéale de l'empereurcitoyen ${ }^{167}$. Après quoi, Honorius n'a plus le choix. Il dispose de tout ce dont il a besoin pour être un bon empereur: la légitimité par le sang et l'exemple apportés par son père, les victoires et l'exemple de Stilicon, qui demeure à ses côtés, son propre mérite. Il ne lui reste plus qu'à agir, et l'éloge l'a en fait privé de toute alternative. Un tel discours est signifiant à la fois pour Honorius, et pour le public qui l'écoute: il faut montrer qu'Honorius est effectivement capable de suivre cette voie.

\section{Conclusion}

Les références aux empereurs du passé créent un programme politique que le poète propose/impose au Prince via le panégyrique. En particulier, Claudien utilise la double référence impériale à Théodose et à Trajan de manière à ce que ces deux modèles se complètent pour rendre compréhensible et acceptable la situation politique en Occident. Il faut intégrer Stilicon à la lignée familiale pour le rendre légitime, et montrer que le pouvoir confié à Honorius ne se justifie pas que par des raisons dynastiques. Les deux empereurs, quand ils sont associés, remplissent pleinement ce qui constituait les vues politiques de Théodose, qui a souhaité à la fois être assimilé à Trajan pour légitimer sa propre place, et établir une transmission dynastique du pouvoir impérial - ce qui pourrait contredire l'idée du choix du meilleur... sauf si justement Trajan devient un ancêtre et qu'en outre Stilicon, excellent dux, se voit intégré dans la lignée. La paix et l'unité de Rome dépendent de son intégration dans la famille impériale: Claudien crée l'image d'une concorde de nature dynastique et familiale, seule capable d'éviter une nouvelle guerre civile. Mais Trajan ne peut évidemment pas être présenté comme un ancêtre du régent, et à lui seul, il ne suffit donc pas: c'est par la figure de Théodose que Stilicon justifie sa place, par l'intermédiaire de l'union de sa fille au Prince. Quant à Honorius, il va devenir un nouveau modèle : celui où transmission dynastique et vertu peuvent être compatibles. L'importance du récit de son éducation sous le patronage de Théodose justifie le choix de ce dernier de faire de ses fils ses successeurs : il se comprend s'il pensait pouvoir régner assez longtemps pour les éduquer et les rendre vertueux. Or sa mort prématurée l'en a empêché, mais Claudien lui substitue Stilicon. En s'appuyant sur une partie de la propagande officielle théodosienne, il peut en outre remonter jusqu'à Trajan et offrir ce modèle de gouvernement au nouveau Prince : il se fait lui aussi le relais de l'éducation d'Honorius. Une telle revendication généalogique n'est donc pas seulement une allusion à l'idéologie théodosienne en ce qui concerne ses prétentions dynastiques: elle se double d'intentions politiques précises. Il s'agit de souligner la continuité qui unit Théodose et Stilicon pour légitimer ce dernier à l'intention du peuple romain et inciter Honorius à se distinguer. La répartition du pouvoir entre Stilicon et Honorius a de plus l'avantage de pouvoir contenter une part plus large du public: à la fois les partisans d'un pouvoir monarchique et les partisans du modèle 
civique du princeps. Dans une époque de mutation, marquée par la diffusion du christianisme et de nouveaux modèles de gouvernement, Claudien nous donne donc une image du Prince qui tienne compte de l'évolution des mentalités de son temps, et qui s'adresse autant au Prince, pour lui indiquer comment il doit agir, qu'au public, pour l'assurer du fait que sous Honorius l'Empire sera bien gouverné. Pour autant, il le fait sans sacrifier sa conception personnelle du pouvoir impérial : dans le contexte qui est le sien, choisir de se référer à l'ancienne tradition romaine est un manifeste politique. De plus, les références impériales semblent s'inscrire dans un fonctionnement énonciatif particulier selon lequel, à côté des passages de discours direct (de Théodose, de Rome, d'Honorius lui-même) qui fonctionnent comme des documents " historiques », les effets de flou dans la bouche du poète (qui permettent de confondre les protagonistes) viennent orienter de façon subjective le sens de ces discours.

La conception du prince idéal selon Claudien est cohérente avec celle que nous donnent certains panégyriques antérieurs (le Panégyrique de Trajan de Pline ou le Panégyrique de Théodose de Pacatus, par ex.), mais s'il s'inspire de ces pièces et s'il y fait clairement référence, c'est aussi pour en faire quelque chose de différent, qui est très intéressant au niveau du fonctionnement du discours de louange : il joue sur la différence entre l'éloge qui loue le prince parce qu'il est vertueux, et l'éloge qui le loue s'il se montre tel. Claudien refaçonne la synkrisis et les codes génériques pour imposer derrière le discours convenu sa propre vision politique. L. Pernot récapitule les différentes manières de cacher un blâme derrière un éloge ${ }^{168}$; le silence peut ainsi avoir deux significations : on tait ce qui ne sert pas l'éloge pour louer, ou bien on tait ce qui sert l'éloge afin de blâmer. On peut aussi créer au cœur de l'éloge une discordance, en louant un personnage pour des qualités qu'il n'a pas. En définitive, il apparaît que la vérité de l'éloge se cache au moins autant dans ce qui est tu et dans la non-adéquation entre le sujet et les vertus célébrées que dans ce qui est dit. Selon la personne à qui Claudien attribue les vertus louées (Honorius, Stilicon, un ancêtre) et selon la manière dont il justifie la non-adéquation entre ces vertus et son destinataire (est-elle à mettre au compte de sa jeunesse? de sa faiblesse personnelle? de son entourage? du modèle qu'il suit, occidental ou oriental ?), le discours revêt un sens plus ou moins polémique. En outre, il faut bien comprendre que les grands modèles qu'il convoque superposent en réalité plusieurs significations: sont-ils des ancêtres, des modèles de vertus indépassables, des modèles à surpasser? Le discours officiel avant Claudien les représente lui aussi d'une manière qui n'est pas univoque : le modèle Trajan ne signifie pas la même chose pour Pline, pour Théodose au début de son règne, ou pour Théodose à la fin de son règne. Claudien, qui en est bien conscient, en joue.

Il apparaît ainsi selon nous que l'étude de la mémoire des figures impériales aide à comprendre comment la pensée politique de Claudien et l'image qu'il donne du prince se construisent au fil de ses poèmes politiques. Le poète a une vision politique cohérente qui se développe dans son œuvre via une multitude d'échos. Cette vision concorde en grande partie avec celle de Stilicon, mais elle ne lui est pas complétement subordonnée, et il sait l'adapter ou la moduler selon les circonstances. Au fil du temps, on passe d'un discours qui vise à justifier la « confiscation » du pouvoir par Stilicon à un discours qui montre à Honorius ce qu'il doit faire pour mériter son sceptre et être un bon prince, puis qui montre enfin qu'il peut être un bon prince. La réalité et sa représentation entretiennent dans le panégyrique un rapport très subtil : le discours 
crée et met en forme sa propre réalité, jusqu'à se faire performatif, et modeler le personnage loué. Le miroir des princes est en effet un miroir déformant, qui ne donne ni un reflet identique, ni un reflet simplement enjolivé du prince. Dans le contexte d'une hostilité certaine d'au moins une partie des citoyens de l'Empire envers Stilicon, Claudien façonne une image idéale qui correspond à son programme politique et qu'il applique à Honorius - personnage suffisamment malléable, du moins dans les premières années de son règne, pour qu'il puisse se le permettre : Honorius règne, et Stilicon gouverne; mais si Honorius gouvernait, il le ferait exactement comme le fait Stilicon.

\section{BIBLIOGRAPHIE}

\section{Textes anciens}

Claudian, with an English transl. by M. PLATNAUER, The Loeb Classical Library. Latin Authors 135-136, Londres, W. Heinemann, 1922, 2 vol.

Claudian, Panegyricus de sexto consulatu Honorii Augusti, ed., transl., and literary commentary by M. DEWAR, Oxford, Clarendon Press, 1996.

Claudien, CEuvres. II, Poèmes politiques : 395-398, texte établi et trad. par J.-L. CHARLET, CUF. Série latine 358, Paris, Les Belles Lettres, 2000, 2 vol.

Panégyriques latins. III, XI-XII, texte établi et trad. par É. GALLETIER, CUF, Paris, Les Belles Lettres, 1955.

Pline le Jeune, Panégyrique de Trajan, préf., éd. et commenté par M. DURRY, Coll. d'études anciennes Paris, Les Belles Lettres, 1938.

\section{Études modernes}

AUSTIN J. L. 1970, Quand dire c'est faire = How to Do Things with Words, trad. G. Lane, L'ordre philosophique, Paris, Éd. du Seuil.

BENNETT J. 2001, Trajan. Optimus Princeps, Bloomington, Indiana University Press.

BORN L. K. 1934, « The Perfect Prince According to the Latin Panegyrists », AJPh 55, 1, p. 20-35.

BRAUND S. M. 1998, «Praise and Protreptic in Early Imperial Panegyric: Cicero, Seneca, Pliny », in M. WHITBY (ed.), The Propaganda of Power. The Role of Panegyric in Late Antiquity, Mnemosyne.

Suppl. 183, Leyde, Brill, p. 53-76.

BURDEAU F., CHARBONNEL N., HUMBERT M. 1964, Aspects de l'Empire romain, Paris, Presses universitaires de France. 
BUREAU B. 2009a, « Idealised Past and Contested Tradition: Claudian's Panegyric for the Sixth Consulship of Honorius and Prudentius' Contra Symmachum » [en ligne]. URL : hal-univlyon3.archives-ouvertes.fr/hal-00881745.

- 2009b, « Irrévérence de la révérence et réverence de l'irrévérence : le Contre Eutrope et le Pané gyrique pour le sixième consulat d'Honorius de Claudien ", in B. DELIGNON, Y. ROMAN (éd.), Le poète irrévérencieux. Modèles hellénistiques et réalités romaines. Actes de la table ronde et du colloque organisés les 17 octobre 2006 et 19 et 20 octobre 2007 par l'ENS LSH, l'Université Lyon 2, et l'Université Lyon 3, Coll. du Centre d'études romaines et gallo-romaines 32, Lyon, Université Jean Moulin-Lyon 3, CERGR, p. 279-313.

CAMERON A. 1969, «Theodosius the Great and the Regency of Stilico », HSPh 73, p. 247-280.

- 1970, Claudian. Poetry and Propaganda at the Court of Honorius, Oxford, Clarendon Press.

CHARLET J.-L. 2009, « Nerva et Trajan dans la pensée politique de Claudien », in O. DEVILLERS, J. MEYERS (éd.), Pouvoir des hommes, pouvoir des mots, des Gracques à Trajan. Hommages au Professeur Paul-Marius Martin, Bibliothèque d'études classiques 54, Louvain, Peeters, p. 559-566.

- 2014, « Références allusives dans le panégyrique de Claudien pour le sixième consulat d'Honorius », Il calamo della memoria 6, p. 145-153.

CHAUSSON F. 2003, « La généalogie du prince dans la pratique de l'éloge impérial aux $\mathrm{III}^{\mathrm{e}}-\mathrm{VI}^{\mathrm{e}}$ siècles », in I. COGITORE, F. GOYET (éd.), L'éloge du prince. De l'Antiquité au temps des Lumières, Des Princes, Grenoble, ELLUG, p. 105-123.

- 2007, Stemmata Aurea : Constantin, Justine, Théodose. Revendications généalogiques et idéologie impériale au I $V^{e}$ siècle ap. J.-C., Atti del Centro Studi e Documentazione sull'Antichità Classica. Monografie a supplemento degli Atti 26, Rome, L'Erma di Bretschneider.

CIZEK É. 1983, L'époque de Trajan. Circonstances politiques et problèmes idéologiques, trad. C. FRANŢESCU, Coll. d'études anciennes, Bucarest, Editura ştiinţificà şi enciclopedică - Paris, Les Belles Lettres. DEMOUGEOT É. 1951, De l'unité à la division de l'Empire romain (395-410). Essai sur le gouvernement impé rial, Paris, A. Maisonneuve.

DUVAL Y.-M. 1984, « La Figure de Théodose chez Claudien », in D. GAGLIARDI (ed.), La Poesia tardoantica: tra retorica, teologia e politica. Atti del V corso della Scuola superiore di archeologia e civiltà medievali presso il Centro di cultura scientifica "E. Majorana", Messine, Centro di studi umanistici, p. 133-185.

FARGUES P. 1933, Claudien : études sur sa poésie et son temps, Paris, Hachette.

GARAMBOIS-VASQUEZ F. 2007, Les invectives de Claudien. Une poétique de la violence, Bruxelles, Éd. Latomus.

GUIPPONI-GINESTE M.-F. 2004, « Poésie, pouvoir et rhétorique à la fin du $4^{\mathrm{e}}$ siècle après J.-C. : les poèmes nuptiaux de Claudien », Rhetorica 22, 3, p. 269-296.

-2007, « Le retour du prince à Rome : voyage initiatique entre parcours réel, symbolique et textuel dans le Panégyrique pour le VI ${ }^{e ̀ m e}$ consulat d'Honorius de Claudien », Camenae 2 [en ligne]. URL : http://www.paris-sorbonne.fr/IMG/pdf/MF_Gineste.pdf.

- 2010, Claudien : poète du monde à la cour d'Occident, Études d'archéologie et d'histoire ancienne, Paris, De Boccard. 
- 2011, « Modalités et significations de la uox poetae dans l'épopée historique de Claudien, De bello Getico ", in É. RAYMOND (éd.), Vox poetae. Manifestations auctoriales dans l'épopée gréco-latine. Actes du colloque organisé les 13 et 14 novembre 2008 par l'Université Lyon 3, Lyon, CEROR, p. 299-313.

HEIM F. 1992, La théologie de la victoire. De Constantin à Théodose, Théologie historique 89, Paris, Beauchesne.

LACHAUD F., SCORDIA L. (éd.) 2007, Le Prince au miroir de la littérature politique de l'Antiquité aux Lumières, Mont-Saint-Aignan, Publications des universités de Rouen et du Havre.

LEFEBVRE S. 2003, «Évolution du vocabulaire dans les hommages publics au Prince ( $\mathrm{e}^{\mathrm{er}}-\mathrm{III}^{\mathrm{e}}$ siècles) », in I. COGITORE, F. GOYET (éd.), L'éloge du prince. De l'Antiquité au temps des Lumières, Des Princes, Grenoble, ELLUG, p. 50-64.

L'HUILLIER M.-C. 1992, L'Empire des mots. Orateurs gaulois et empereurs romains, $3^{e}$ et $4^{e}$ siècles, Annales littéraires de l'Université de Besançon 464, Paris, Les Belles Lettres.

MOLIN M. 1989, « Le Panégyrique de Trajan : éloquence d'apparat ou programme politique néostoïcien? », Latomus 48, 4, p. 785-797.

PASCHOUD F. 1967, Roma Aeterna. Études sur le patriotisme romain dans l'Occident latin à l'époque des grandes invasions, Bibliotheca helvetica romana 7, Rome, Institut suisse de Rome.

PERNOT L. 1993, La rhétorique de l'éloge dans le monde gréco-romain, Coll. des études augustiniennes. Série Antiquité 137-138, Paris, Institut d'études augustiniennes, 2 vol.

- 2015, Epideictic Rhetoric. Questioning the Stakes of Ancient Praise, Ashley and Peter Larkin Series in Greek and Roman Culture, Austin, University of Texas Press.

ROCHE P. A. (ed.) 2011, Pliny's Praise. The Panegyricus in the Roman World, Cambridge, Cambridge University Press.

SERBAT G. (dir.) 1996, Grammaire fondamentale du latin. IV, L'emploi des cas en latin. 1, Nominatif, vocatif, accusatif, génitif, datif, Bibliothèque d'études classiques 8 , Louvain, Peeters.

STRUTHERS L. B. 1919, « The Rhetorical Structure of the Encomia of Claudius Claudian », HSPh 30, p. 49-87.

WALLACE-HADRILL A. 1982, « Civilis Princeps: Between Citizen and King », JRS 72, p. 32-48.

WARE C. 2013, «Learning from Pliny: Claudian's Advice to the Emperor Honorius », Arethusa 46, p. 313-331.

ZARINI V. 2007, «Le Prince au miroir des panégyriques versifiés dans la latinité tardive », in $\mathrm{F}$. LACHAUD, L. SCORDIA (éd.), Le Prince au miroir de la littérature politique de l'Antiquité aux Lumières, Mont-Saint-Aignan, Publications des universités de Rouen et du Havre, p. 45-67.

- 2010, « Rome au miroir de son passé chez les poètes latins de l'Antiquité tardive », communication prononcée à l'Università degli Studi Federico II le 19 avril 2010 [en ligne]. URL : http://www.studitardoantichi.org/einfo2/file/1275558170-ZARINI.pdf.

\section{NOTES}

1. LACHAUD, SCORDIA (éd.) 2007, p. 425 sq., offre une bibliographie générale sur le sujet. En particulier, sur le miroir des princes dans les panégyriques en vers de l'Antiquité tardive, voir la contribution de V. Zarini dans le même volume (ZARINI 2007). L'auteur 
discute en introduction la définition du "miroir des princes», et en choisit une définition large, qui ne se cantonne pas au traité adressé au prince mais inclut notamment le genre du panégyrique. Puis il aborde entre autres le Panégyrique pour le quatrième consulat d'Honorius, où Claudien «a l'habileté de placer aux v. 214 sq. dans la bouche de Théodose, censément en 393, un long discours pédagogique à son fils alors âgé de neuf ans, ce qui lui permet de "faire la leçon" à l'autocrate sans outrecuidance " (p. 49).

2. Sur les qualités de Trajan et de son règne qui ont fait de lui un exemple de bon prince, voir notamment cIzeK 1983 (en particulier p. 198 sq. sur le respect mutuel de Trajan et du Sénat; p. 209 sq. sur le système politique et idéologique fondé sur l'équilibre entre conquêtes extérieures et le compromis dans la politique intérieure; p. 212 et 225 sur la clementia de Trajan; p. 233 sur Trajan et la libertas); BENNETT 2001 (en particulier p. 104 sur son titre d'optimus princeps; p. 107 et 210 sur les relations entre Trajan et le Sénat; p. 73 sur la libertas sous Trajan; p. 63 sq. sur le panégyrique de Pline comme miroir des princes); Roche 2011 (p. 6 sur les qualités que possède Trajan et qui font le bon prince chez Pline; p. 8 sur le fait que ces vertus se réunissent en une idée, l'autolimitation du pouvoir absolu).

M. Molin (1989) rappelle que le travail de réécriture attesté par Pline lui-même témoigne du fait qu'on a dans le Panégyrique de Trajan autre chose qu'un simple éloge de circonstance. Il vise à contribuer à justifier la nomination de Trajan, car, en l'absence de règle de succession à l'Empire, et après des crises qui ont entouré d'autres adoptions, il importe particulièrement de mettre en avant les qualités qui l'expliquent (voir Pline le Jeune, Pan. 8, 5 et 94, 4). Pline se donne ainsi pour but « de transfigurer l'empereur pour le proposer à lui-même puis à ses successeurs comme le Prince idéal dont la conduite pourra servir de modèle » (p. 790 ; voir Pline le Jeune, Ep. 3, 18, 2). M. MoLIN dresse alors une liste des vertus louées par Pline (p. 791-792). Mais cet éloge est cohérent avec la manière dont l'arrivée au pouvoir de Trajan a été reçue : Optimus est un titre qui lui a été décerné tout à fait officiellement par sénatus-consulte en 98, et qui est attesté sur des monnaies et des inscriptions (p. 794 ; Pan. 2, 7 et 88, 4). Le titre sera ensuite porté par certains de ses successeurs, mais il restera attaché à Trajan en particulier. Voir LEFEBVRE 2003, p. 58-59 sur la fortune de l'appellation Optimus.

Au sujet de la postérité d'un tel modèle, voir BURDEAU, CHARBONNEL, HUMBERT 1964 sur les vertus du bon empereur dans les Panégyriques latins.

3. Sur la définition du prince idéal chez Claudien : voir BORN 1934, p. 25-30.

4. En ce qui concerne la topique de l'éloge, nous renvoyons à l'ouvrage fondamental de L. Pernot (1993, en particulier p. 134-178 pour l'éloge des personnes), ainsi qu'aux traités de rhétorique antiques et aux recueils de progymnasmata (voir PERNOT 1993, p. 56-71 pour le monde grec, et $\mathrm{p}$. 106-111 pour le monde romain).

5. C'est ainsi que P. Fargues semble lire ces allusions : Claudien suivrait ici simplement les préceptes de Ménandre en louant les ancêtres et la patrie d'Honorius, ce qui permet de surcroît de masquer l'insignifiance du jeune empereur (FARGUES 1933, p. 198-199).

6. C'est ce qu'en dit Claudien, du moins.

7. Nous nous référerons pour le texte à l'édition des poèmes politiques de Claudien par J.-L. Charlet dans la CUF (2000) lorsqu'elle est disponible. Pour les autres poèmes de Claudien, nous utiliserons l'édition de M. Platnauer (1922). Les traductions seront les nôtres. 
8. Nous suivons ici la reconstitution chronologique proposée par J.-L. Charlet dans l'introduction de son édition (CHARLET 2000, I, p. IX-XXXV).

9. CHARLET 2000, I, p. X-XVIII.

10. CHARLET 2000 , I, p. XV.

11. CAMERON 1970, p. 62. Sur la relation entre Honorius et Stilicon, voir FARGUES 1933, p. 120-127.

12. Sur le problème posé par le testament de Théodose et la régence de Stilicon, voir par ex. DEMOUGEOT 1951, p. 102 ; CAMERON 1969, p. 274-280 ; CAMERON 1970, p. 42-44 ; CHARLET 2000, I, p. XVII.

13. Voir ci-dessous.

14. CHARLET 2000, I, p. XVI.

15. Plusieurs choix lexicaux dans les premiers vers du panégyrique semblent établir un lien avec la scène décrite dans la préface, en particulier alitibus au v. 9 et fouet au v. 11 (faut-il y ajouter aquilis au v.16?), qui renvoient au monde des oiseaux. Au v. 14, l'expression regnum cum luce sonne à elle seule comme un résumé de l'épisode (la même idée apparaît aux v. 153-154 du Panégyrique pour le quatrième consulat d'Honorius; en réalité Claudien travestit la réalité, le premier consulat d'Honorius ne coïncidant pas exactement avec sa naissance - il devait être plutôt dans sa deuxième année : voir CHARLET 2000, II, p. 163, n. 3 sur la p. 16). Plus loin, au moment où Théodose confie à Stilicon le soin de ses deux fils, il emploie le verbe foue au v.153, et l'expression crescentes [...] fetus à la fin du v. 157 rappelle educere fetus à la fin du v. 1 de la préface.

16. CHARLET 2000, I, p. 177.

17. À l'inverse, dans le Consulat de Stilicon, le poète passera bien vite sur les origines et la naissance de Stilicon, qui ne sont pas aussi glorieuses qu'il aurait pu le souhaiter ; mais il faut dire qu'en ce qui concerne le général, il aura ensuite suffisamment de matière pour exalter ses hauts faits...

18. CAMERON 1970, p. 39. Voir aussi BUREAU 2009b, p. 296, qui reprend en note l'analyse juridique de J. M. O'Flynn dans Generalissimos of the Western Roman Empire, Edmonton, University of Alberta Press, 1983, p. 45-46.

19. Sur les reprises ultérieures de ce «testament », voir CAMERON 1970, p. 49 sq.

20. La première de ces occurrences, la prière des v. 33-38, annonce la valeur de l'exploit guerrier, et la référence à Ovide que repère J.-L. Charlet (CHARLET 2000, I, p. 36, n. b) consacre le lien entre cette valeur et l'exercice du pouvoir impérial, en la rattachant à Auguste. Dans le reste du poème, et comme le veut la loi du genre, c'est le poète qui assume à lui seul la parole et qui destine l'éloge à Honorius, en usant massivement de l'adresse à la $2^{\mathrm{e}}$ personne (on verra que ce sera différent dans les autres panégyriques impériaux). M.-F. Guipponi-Gineste a montré comment, dans un autre genre que le panégyrique, l'épopée historique (et plus précisément dans La Guerre contre les Gètes), Claudien tire parti des interventions de la uox poetae dans la narration épique pour mettre en avant la signification partiale qu'il veut donner aux événements racontés et pour inclure dans un poème, qui demeure épique, des éléments épidictiques (GUIPPONIGINESTE 2011). 
21. Voir CAMERon 1970, p. 42-44 sur ce passage. Il faut noter que Théodose, s'il demande à Stilicon de veiller sur ses fils et de les protéger comme un père, ne définit pas ici exactement - juridiquement - son statut (CHARLET 2000, I, p. XVII).

22. Claudien, Panégyrique pour le troisième consulat d'Honorius 142-144 : «À son arrivée au palais, le chef ordonne que tout le monde sorte et s'adresse à son gendre en ces termes".

23. La vertu première du dirigeant semble être le talent à la guerre (v. 59 et 88). D'ailleurs, la figure de Théodose que nous présente Claudien est essentiellement guerrière, et les vœux qu'il formule pour son tout jeune fils concernent eux aussi le prestige militaire (v.33-38). L'éducation qu'il lui donne est celle du héros guerrier (v. 39-60), faisant d'Honorius un nouvel Achille (v. 60-61). C'est la valeur militaire de Stilicon qui justifie en premier lieu sa nomination comme tuteur, et c'est la conquête du monde que le poète laisse entrevoir à Honorius et à Arcadius à la fin du poème.

24. Ici, elle est garante de la concordia dans l'Empire : l'usurpation d'Eugène, source de guerre civile, est un crime contre la fides : v. 63.

25. Claudien, Panégyrique pour le troisième consulat d'Honorius 144-146: "Stilicon, puissant guerrier, toi qui es ma force dans les batailles et dont la fidélité m'a été prouvée en temps de paix - qu'ai-je accompli dans les combats sans toi ?»

26. Claudien confirme aux v. 24 sq. du Panégyrique pour le quatrième consulat d'Honorius la posture de l'aïeul, grand chef de guerre, et à l'origine d'une glorieuse lignée. Le début du second livre du Contre Rufin va dans ce sens, et même plus loin encore. Stilicon y réunit toutes les fonctions impériales, y compris celles qu'il ne devrait pas posséder; c'est que l'heure est grave : Rufin est tombé, mais l'action de Stilicon en Grèce est très controversée et source de tensions avec l'Orient (CHARLET 2000, I, p. XXIII).

27. Claudien, Panégyrique pour le troisième consulat d'Honorius 51-52: «Et pour stimuler encore davantage ton amour de la guerre, il énumérait les hauts faits de ton aïeul ».

28. À moins de ne pas faire de tu pignora solus / nostra foue un développement de tu curis succede meis au v.152-153, auquel cas les curae en question peuvent bien désigner le gouvernement de l'Empire. C'est ainsi que le comprend A.Cameron: "Stilico is to succeed to all Theodosius' responsabilities -that is to rule the whole Empire just as Theodosius had done » (CAMERON 1970, p. 43).

P. 49-50, A. CAMERON cite les autres passages dans lesquels Claudien revient sur le legs de Théodose : pour la plupart, ils sont bien plus francs en ce qui concerne les fonctions politiques de Stilicon. Remarquons notamment qu'au v. 308 de l'Épithalame pour les noces de l'Empereur Honorius Claudien use de la même expression, rerum [...] habenae pour parler du pouvoir laissé à Stilicon que lorsqu'il parle de la fonction impériale d'Honorius confiée à lui par son père dans le panégyrique pour le troisième consulat (v. 83, voir ci-dessous).

29. Le fait que Stilicon gouverne pour Honorius apparaît bien dans la manière dont le discours de Théodose est amené, car le moment où ce dernier transmet son pouvoir au régent a été annoncé par le v. 110, lorsque le poète dit que Théodose choisit de différer l'heure de sa mort pour confier l'Empire à... son fils. Y.-M. Duval (1984) parle ainsi de "fondu-enchaîné » (p.147) puis de «raccourci» (p.148) à propos du moment où l'arrivée d'Honorius à Milan pour y retrouver son père se transforme en entretien entre ce dernier et Stilicon.

30. CHARLET 2000, I, p. XVI et p. 177-178, n. 3 (sur la p. 39). 
31. Claudien, Panégyrique pour le troisième consulat d'Honorius 109-110 : «l'Auguste différa le moment de se confier au ciel qui l'appelait, jusqu'à ce qu'il t'eût transmis l'empire du monde pacifié en mains propres ».

32. Sur les affinités entre éloge et conseil, voir PERNOT 1993, p. 710-724. Malgré la distinction théorique entre épidictique et délibération, l'éloge et le conseil sont liés (l'éloge peut intervenir à l'appui du conseil, le conseil peut apparaître dans le prolongement de l'éloge, l'éloge peut se faire au futur pour orienter le sujet vers la manière d'agir qu'on lui conseille, et enfin l'éloge peut apparaître sous la forme d'un conseil), et l'éloge peut donc devenir le lieu de l'exposition d'une véritable philosophie politique qui dépasse le simple éloge de circonstance. L. Pernot écrit: "Suivant une conception largement répandue dans l'Antiquité, il est admis que l'éloge offre aux auditeurs un modèle de vertu et les incite à l'imiter»(p.717). En ce sens, le panégyrique impérial, hommage et encouragement, se fait aussi définition du Prince idéal : il y a toujours deux niveaux dans l'éloge, le niveau particulier de la louange du sujet choisi, et le niveau général de la méditation sur ce que doit être un bon maître. Voir aussi PERNOT 2015, p. 93.

33. Nous nous sommes concentrée ici sur le rôle joué par Théodose dans ce poème en lien avec la question de la légitimité en ce qui concerne sa succession. Y.-M. Duval (1984, p. 149-150) se penche en outre sur la description de son apothéose et du nouvel âge d'or qu'il doit contempler depuis le ciel, et il relie ces accents optimistes à l'arrivée récente en Occident de la nouvelle de la chute de Rufin.

34. CAMERON 1970, p. 93.

35. Claudien, Panégyrique pour le quatrième consulat d'Honorius 18-20: «Elle n'est pas indigne d'honneur, et Mars ne la connaît pas d'hier, la lignée d'Ulpius, cette maison ibère qui a constellé le monde de diadèmes ».

36. CHARLET 2000, II, p. 7, n.d, donne des références antiques sur cette filiation. F. Chausson rappelle bien que, si dès le début de son règne Théodose a été présenté comme un descendant de Trajan, cette filiation ne peut pas être confirmée d'un point de vue historique (CHAUSSON 2007, p. 257).

Sur la généalogie du prince dans l'éloge impérial tardif, voir CHAUSSON 2003, en particulier en ce qui concerne les liens nécessaires entre ce qui est affirmé dans les éloges et les autres moyens de diffusion du discours impérial (monnaies, statues, titulatures...) : «le panégyrique, comme l'épigraphie, la monnaie ou la statuaire, est l'expression d'un discours officiel voulu par le Prince et la naissance, révélatrice d'une identité assumé ou revendiquée, y joue un rôle éminemment politique » (p. 123).

37. CAMERON 1970, p. 368-369, réfute l'idée d'un refus de la part de Claudien de parler de la naissance orientale d'Honorius (réfutant STRUTHERS 1919, p.61). Certes, il en fait mention (v. 128-129), mais il insiste bien plus sur son ascendance espagnole, ici et dans les autres poèmes, pour le rattacher à un type de gouvernement proprement occidental.

38. CHAUSSON 2007, p. 210, n. 56.

39. CHAUSSON 2007, p. 211.

40. CHAUSSON 2007, p. 214.

41. CHAUSSON 2007, p. 216. 
42. Chausson 2007, p. 227. Cf. Thémistius, 34, 7, où les Antonins sont nommés par rapport à Théodose «ses aïeux, ses concitoyens, les fondateurs de sa lignée » (la traduction est celle de F. Chausson).

43. CHAUSSON 2007, p. 253.

44. CHAUSSON 2007, p. 231-232. Voir les p.237-252 pour des références historiographiques au sujet du lien familial entre Théodose et les Antonins. Parmi celles-ci, l'Epitome de Caesaribus « témoigne de manière exemplaire que, dans la Rome de Stilicon, les revendications antonines de Stilicon suscitaient de vifs échos» (p. 243). L'auteur de l'Histoire Auguste, lui, «mécontent des jeunes princes placés sous la régence de Stilicon, peut-être favorable à un régent incarnant un authentique choix du meilleur [...], nostalgique d'une antique Res publica sénatoriale» (p. 253), remet fortement en question l'idéologie dynastique de Théodose. En creux, l'ouvrage peut ainsi nous aider à mieux comprendre les intentions qui sont celles de Claudien.

45. Sur l'influence de Pline sur Pacatus, et la constitution d'une "légende de Théodose » (dont Claudien se fait en partie l'écho), voir Roche 2011, p. 178 sq. Dans le contexte d'usurpations successives qui est celui de l'Empire à l'époque de Théodose, Trajan apparaît comme le meilleur empereur dont on puisse se réclamer, et il a en outre pour lui son origine espagnole.

46. CHARLET 2009, p. 561, donne d'autres exemples montrant la diffusion de l'idée de lien dynastique juste avant l'époque de Claudien.

47. Cf. Pline le Jeune, Pan. 7, 4. Claudien dira la même chose de Stilicon (Consulat de Stilicon 2, 279-339 et 3, 87-88).

Sur la recusatio imperii comme rituel garantissant la distinction entre le Prince et le tyran, voir WALLACE-HADRILL 1982, p. 36-37.

48. Sur les vertus de Théodose chez Pacatus, voir L'HUILLIER 1992, p. 343.

49. Pacatus, Panégyrique de Théodose $12,1:$ « toi, tu ne dois ton élection à l'empire ni à la brigue, ni à l'occasion, ni à la parenté. Tu étais étranger à la famille impériale, tu étais appelé en tiers au gouvernement et tu étais forcé de l'accepter malgré toi : je dis bien, malgré toi. »

50. Sur les exempla chez Claudien, dont Trajan et Marc Aurèle, ainsi que Théodose, surpassés par Honorius (Panégyrique pour le sixième consulat d'Honorius 333-341 pour les premiers, Panégyrique pour le quatrième consulat d'Honorius 430-431 pour le troisième), voir FARGUES 1933, p. 211.

51. CAMERON 1970, p. 341.

52. Sur les jugements négatifs à l'encontre d'Honorius, voir CAMERON 1970, p. 154.

53. C'est ce qu'on lit en tout cas dans l'Histoire Auguste : voir CHAUsson 2007, p. 190, 247, 249, 251, 253-254.

54. Pacatus se fait l'écho de l'installation dans les esprits de la transmission dynastique du pouvoir lorsqu'il loue Théodose, non pas pour avoir nommé consuls ses amis à la place de ses fils, comme le faisait Thémistius, mais pour les avoir nommés avant ses fils (Panégyrique de Théodose 16, 4-5 et 45,3).

Sur l'acceptation de l'idée d'une transmission dynastique du pouvoir au cours du $\mathrm{IV}^{\mathrm{e}} \mathrm{s}$., voir FARGUES 1933, p. 146-147 : «Avec Constance et Constantin, le principe de l'hérédité s'est affermi ». Fargues est cependant d'avis que Claudien use aussi de cette idée pour 
légitimer le pouvoir de Théodose, en ne faisant que passer sur l'idée de son mérite. Nous ne partageons pas cette analyse.

Sur l'équilibre délicat maintenu dans les Panégyriques latins entre hérédité et mérite personnel, voir BURDEAU, CHARBONNEL, HUMBERT 1964, p. 58-60.

55. Saint Jérôme le qualifie de semibarbarus proditor (Ep. 123, 16, 2).

56. Voir GUIPPONI-GINESTE 2010, p. 93-95 sur la signification du thème marin dans la description de la trabée d'Honorius : il concourt à inscrire le jeune Empereur dans la grandeur de la gens Ulpia.

57. Sa fonction de père est rappelée quand le poète commence à s'adresser à Honorius, au v.60. Au v.127, Claudien insiste encore sur l'origine espagnole de son père. L'appellation est bien sûr à comprendre par rapport à Honorius, mais il nous semble que cette insistance peut être liée avec le fait que Stilicon est l'autre personnage à être appelé ainsi, et que le poète travaille de la sorte à confondre l'un et l'autre.

58. Voir CHARLET 2000, II, p. 158, n. 1 (sur la p. 9) sur les mérites militaires de Théodose qui lui ont valu la pourpre impériale et sur les échos à Pacatus et à Pline dans ce passage.

59. Plus loin (v.315-319), la clementia sera pourtant placée plus haut que la valeur guerrière. Y.-M. Duval explique bien que si le poème «consacre plus de quatre cents vers à narrer les exploits du grand-père et du père d'Honorius [on] se tromperait en pensant qu'il ne s'agit que d'un exercice d'école ou du simple désir de compenser l'inexistence de l'empereur par le récit des hauts faits de ses ancêtres. Si Théodose l'Ancien tient une telle place dans ce Panégyrique - avant le rôle qui lui sera imparti dans La Guerre contre Gildon, c'est peut-être bien à cause de ce qui se passe à ce moment en Afrique où il s'était naguère couvert de gloire, contre le frère aîné de Gildon (v. 18-40)» (DUVAL 1984, p. 156). Claudien sait toujours adapter le lieu commun et son propos aux circonstances.

60. Les notes a et b dans CHARLET 2000, II, p. 10, indiquent des rapprochements avec plusieurs passages tirés d'autres poèmes de Claudien et dans lesquels il est question de Stilicon : « La figure de Stilicon, homme providentiel, et celle des Théodose tendent à se confondre dans l'imaginaire politique de Claudien. »

61. Claudien, Panégyrique pour le quatrième consulat d'Honorius 99-100: «Que par-là les siècles apprennent que pour l'homme qui aime sa patrie rien n'est indomptable, et que rien n'est sûr pour le coupable.»

62. Claudien, Panégyrique pour le quatrième consulat d'Honorius 203-205: «Plus heureux grâce à cet augure et enorgueilli de ses fils désormais égaux, le père retournait soutenu par ses deux collègues, et sur son char sacré, entourant ses enfants de ses bras, il resplendissait. »

63. Voir ci-dessous.

64. A. Cameron voit dans la contradiction entre le fait de louer Théodose pour avoir obtenu le pouvoir par son mérite et le fait de louer Honorius pour n'avoir jamais connu la condition du priuatus une preuve de l'inconsistance politique de Claudien (CAMERON 1970, p. 378). Au lieu d'une contradiction, nous voyons ici une tension tout à fait productive.

65. Cette tension est rendue particulièrement visible à travers le choix de Trajan: malgré son adoption par Nerva et les déclarations officielles de ce dernier en sa faveur, 
sa position n'était pas légitime tant que le Sénat, et lui seul, ne lui avait pas confié la tribunicia potestas et l'imperium maius. Il n'existait en effet aucune disposition légale permettant à un princeps de déléguer son pouvoir, pas plus qu'il n'existait de principe héréditaire de succession. Sur ce sujet, voir BENNETT 2001, p. 47.

En ce qui concerne Claudien: "Claudian seems to condemn (though obviously only implicitly) the dynastic succession of emperors, when he praises the best emperors of the past [...]. In Claudian's mind, there seems to be a link between automatic dynastic succession and corruption of power » (BUREAU 2009a, p. 12).

66. "The first chapter in an encomium [i.e. le genos] always speaks of the individuals' ethnic and familial background, of cities' founding and ancient history. Epideictic is obsessed with lineage, reflecting the structure and ideals of the society of the Imperial period, which was dominated by the influence of important families and of cities devoted to their national pasts » (PERNOT 2015, p. 95).

67. FARGUES 1933, p. 198-199.

68. Remarquons qu'il n'y a que dans les panégyriques impériaux que l'on trouve ainsi des cas de leçon de gouvernement formulée par un personnage, et non pas assumée par le poète.

69. WARE 2013, p. 325.

70. La comparaison d'Honorius et Arcadius par Théodose fait écho au double discours de Théodose et de son père dans La Guerre contre Gildon. Théodose y blâme le traître Gildon et la complicité de l'Orient, qui menacent de provoquer la discorde civile (v. 235 sq.).

71. J.-L. Charlet indique en outre plusieurs parallèles avec le De clementia de Sénèque (voir les notes dans CHARLET 2000, II, p. 23-25). Les échos que l'on peut déceler avec le Discours sur la royauté de Synésius s'expliqueraient plutôt par une influence commune aux deux auteurs, à savoir la vision politique à l'œuvre dans la rhétorique grecque (cf. CAMERON 1970, p. 321-323).

72. Juste avant (v.313-315), il fait référence aux «monstruosités de la maison des Césars ", et nomme en particulier Néron. Il faut noter que cette référence précise est ambiguë : Néron est l'empereur qui est un bon prince tant qu'il accepte l'influence de Sénèque, mais qui devient tyran quand il s'orientalise. Doit-on comprendre qu'ici Théodose joue le rôle de Sénèque? Et, donc qu'Honorius, qui court le risque de se laisser aller à suivre l'exemple de son frère, ne pourra être un bon prince que tant qu'il acceptera d'écouter les conseils de Théodose/Claudien? Claudien semble aussi ici indiquer à Honorius le danger qui peut se cacher derrière la transmission familiale du pouvoir : elle peut exposer l'Empire à être à la merci des pires individus. Et, quoi qu'il en soit, Claudien/Théodose oppose en regard de l'optimus princeps la triple figure du roi oriental et tyrannique, du roi romain et du mauvais empereur romain (v. 306-310).

73. WARE 2013, p. 325.

74. Dont le talent militaire, à lire Claudien, n'est plus à démontrer, et dont la clémence sera vantée notamment dans La Guerre contre les Gètes aux v. 274-330.

75. Voir GUIPPONI-GINESTE 2010, p. 89-96, sur la description de la trabée d'Honorius : «[L]es détails descriptifs renforcent la dimension religieuse du processus consulaire et l'aspect supra-humain de l'empereur, impassible, assimilé à un dieu solaire. La 
description, en particulier par la comparaison qui introduit un autre lieu, un autre temps, exprime l'universelle et éternelle présence de la majesté impériale » (p. 93).

76. On retrouve l'image des rênes du pouvoir, habenas, tenues par Honorius au v. 422 (voir ci-dessus).

77. Pour $\mathrm{C}$. Ware, célébrer à la fois le sang et la vertu permet de répondre aux attentes de l'Orient et de l'Occident (WARE 2013, p. 9).

78. WARE 2013, p. 330.

79. De même, dans La Guerre contre Gildon, Claudien fait brièvement parler Arcadius dans le sens qu'il souhaiterait (v. 321-324) : il promet de suivre les volontés de Théodose - telles que Claudien nous les transmet - et considère Stilicon comme un membre de sa famille (cognato).

80. Mais prometteur néanmoins, car doté de réelles qualités en puissance : Nostro nec debes regna fauori, / quae tibi iam Natura dedit, «Ce n'est pas à ma faveur que tu dois ton pouvoir, lui qui t'a déjà été confié par la Nature ", lui dit son père aux v. 379-380.

81. La vivacité du rythme de ses phrases marque certes son empressement à agir, mais celui-ci semble bien puéril.

82. Dans le Panégyrique de Théodose (7, 2-6), Pacatus célèbre le fait que Théodose ne soit pas parvenu au pouvoir avant l'âge de la maturité : la trop grande jeunesse fait courir le risque des égarements des passions, et les institutions républicaines prévoyaient un âge minimal pour l'accession à chacune des magistratures.

83. Claudien, Panégyrique pour le quatrième consulat d'Honorius 430-431: «Déjà ton fils t'égale en mérites, et, ce qui dépasse même les attentes, il te surpasse. "

84. Claudien, Panégyrique pour le quatrième consulat d'Honorius 434-436: Pro nobis nihil ille pati nullumque recusat / discrimen temptare sui, non dura uiarum, / non incerta maris, « Pour nous, il n'y a rien que ce héros refuse d'endurer, aucun danger qu'il ne veuille affronter, ni les difficultés des routes, ni les risques des mers ».

85. Sur la périphrase qui désigne Stilicon, voir CHARLET 2000, II, p. 167, n. 1 (sur la p. 34).

86. Claudien, Panégyrique pour le quatrième consulat d'Honorius 439-440: Hunc tamen in primis populos lenire feroces / et Rhenum pacare iubes, «Cependant tu lui ordonnes d'aller apaiser d'abord des peuples farouches, et le Rhin ».

87. Claudien, Panégyrique pour le quatrième consulat d'Honorius 448-449: iuratur Honorius absens / inploratque tuum supplex Alamannia nomen, «en son absence on jure fidélité à Honorius et l'Alamannie, suppliante, invoque ton nom ».

88. CHARLET 2000, II, p. 167, n. 2 (sur la p. 35).

89. On lit des présents de narration au milieu d'un récit au passé aux v.69-70. J.-L. Charlet note à ce propos que cet emploi n'est pas surprenant (CHARLET 2000, II, p. 159, n. 2, sur la p. 10). Et en effet, on voit bien dans ce cas l'effet emphatique de cette irruption circonscrite. Il semble toutefois que le passage qui nous intéresse ici ne fonctionne pas de la même manière : il est majoritairement au présent, car il est censé se rapporter à des événements récents, tandis que les quelques parfaits qui l'émaillent nous projettent soudain dans un passé indéfini.

90. Claudien, Panégyrique pour le quatrième consulat d'Honorius 446-448: Ante ducem nostrum flauam sparsere Sygambri/ caesariem pauidoque orantes murmure Franci/ procubuere solo, «Devant notre chef les Sicambres ont répandu leur chevelure blonde, et les Francs se sont prosternés en murmurant des prières effrayées ». 
91. Sur le sens de hortaris, voir CAMERON 1970, p. 97 : « The most recent commentator on the poem observes that "hortaris" is a device to give Honorius the credit for Stilico's exploit. This is true enough, but it is not the whole reason. When we recall that Stilico's campaign in Greece had ended with Arcadius declaring him a public enemy, we can see at once why Claudian is really so anxious to make out that Stilico was only acting under orders from Honorius. He was matching the order of one Emperor against the order of the other. »

92. WARE 2013, p. 329-330.

93. «Like Trajan (Pan. 12-20), Stilicho is presented as a great imperator, one who has pacified the Rhine, Germany, Gaul, and Greece. Like Trajan, his achievements surpass those of early heroes: the Drusi made treaties with Germany but at great cost, while Stilicho achieves this without bloodshed (IV Cons. 455-57). As a great leader should, he is willing to face every danger by land and sea (434-38). Indeed, in the final section of the panegyric, it is difficult not to take Stilicho as the honorand. » En note, elle évoque en outre les vertus de Stilicon qui viennent compléter ce tableau : "Although Claudian does not discuss Stilicho's virtues here, it is clear from a panegyric of 400 C.E. in honour of Stilicho's consulship that he does not need Theodosius's warnings to govern his passions and seek virtue, since Claudian congratulates him on the fact that all the virtues, having put vice to flight, have taken up residence in his breast (Stil. 2.100-02) » (WARE 2013, p. 329).

94. On peut de plus remarquer à leur sujet toutes les tournures, par ex. les tournures passives, qui évitent soigneusement de faire d'Honorius l'acteur explicite des décisions qui sont décrites.

95. Claudien, Panégyrique pour le quatrième consulat d'Honorius 520-522 : « Déjà tu remplis les casques de ton père ; déjà tu essaies de brandir le javelot de ton aïeul; ce premier entraînement promet de grandes réalisations et retarde les vœux de Rome. »

96. Claudien, Panégyrique pour le quatrième consulat d'Honorius 539 : «Quand tu montes à cheval et que tu joues à imiter la guerre... »

97. Au sujet de la ressemblance d'Honorius avec son père: on sait que Théodose a essayé de montrer sa ressemblance avec Trajan (CHAUsson 2007, p. 242); Pacatus, lui, mentionne la ressemblance de Théodose avec son propre père (Panégyrique de Théodose 6).

98. Claudien, Panégyrique pour le quatrième consulat d'Honorius 518-519: Quantus in ore pater radiat! Quam torua uoluptas / frontis et augusti maiestas grata pudoris!, «Combien ton père resplendit sur ton visage! Quelle grâce farouche sur ton front, et quelle aimable majesté de ta pudeur auguste !»

99. Claudien, Panégyrique pour le quatrième consulat d'Honorius 520-524: Iam patrias imples galeas; iam cornus auita / temptatur uibranda tibi; promittitur ingens / dextra rudimentis Romanaque uota moratur. Quis decor, incedis quotiens clipeatus et auro / squameus et rutilus cristis et casside maior!, «Déjà tu remplis les heaumes de ton père ; déjà tu essaies de brandir le javelot de ton aïeul; ce premier entraînement promet de grandes réalisations et retarde les vœux de Rome. Quelle noblesse, chaque fois que tu t'avances avec ton bouclier, ton armure d'or, ton panache flamboyant, et grandi par ton casque!»

100. Claudien, Panégyrique pour le quatrième consulat d'Honorius 539-541: Cum uectaris equo simulacraque Martia ludis, / quis molles sinuare fugas, qui tendere contum / acrior aut 
subitos melior flexisse recursus?, "Quand tu montes à cheval et que tu joues à imiter la guerre, qui sait fuir tout en souplesse, qui est le plus doué pour lancer la pique ou le meilleur pour faire un demi-tour soudain?»

101. CHARLET 2000 , II, p. 43 , note c.

102. Claudien, Panégyrique pour le quatrième consulat d'Honorius 578-580: [...] convenit in unum / quidquid in orbe fuit procerum, quibus auctor honoris / uel tu uel genitor, "se réunit en un seul lieu tout ce que le monde comptait de nobles, ceux à qui ton père ou toi aviez donné des honneurs ».

103. Les dénégations à ce sujet (Stilicon va rendre le pouvoir : cf. Consulat de Stilicon 2, 52-62) sont contredites par les faits : il le rendra, certes, mais quand?

104. La description du propre mariage de Stilicon avec Sérène au livre 1 du Consulat de Stilicon présentera aussi cette union comme une affaire à la fois publique et privée, en donnant un chef à l'Empire en plus d'un époux à la fille de Théodose. Les v. 76-79 réunissent ainsi (fausse) dynastie et mérite personnel : Stilicon est intégré à la famille et prend la place de Théodose, et Stilicon fait sienne la pourpre impériale qui est mentionnée par son mariage.

105. Même si l'on garde en tête le fait que, Théodose étant mort, il peut représenter à lui seul la famille de chacun des deux futurs époux.

106. Pour des références bibliographiques sur le genre de l'épithalame à l'époque tardive, voir GUIPPONI-GINESTE 2004, p. 271. Nous ajoutons l'ouvrage de S. HORSTMANN, Das Epithalamium in der lateinischen Literatur der Spätantike, Beiträge zur Altertumskunde 197, Munich, K. G. Saur, 2004.

Sur l'arrière-plan politique de ces poèmes nuptiaux, voir GUIPPONI-GINESTE 2004, en particulier p. 279-283 : il s'agit pour Claudien de masquer autant que possible le fait que Stilicon ait précipité le mariage entre Honorius (qui n'avait pas encore quatorze ans) et Marie (qui était à peine nubile) à des fins personnelles et d'exalter à la fois le nouveau couple impérial, mais aussi Stilicon, et la grandeur de Rome due à ses victoires. Alors que les deux moitiés de l'Empire étaient au bord de la guerre civile, Stilicon avait en effet tout intérêt à «asseoir son pouvoir sur autre chose qu'une entrevue secrète dont tout un chacun pouvait contester les décisions occultes" (DUVAL 1984, p. 159). Les v. 28-30 de l'Épithalame font même de cette union le résultat de la volonté de Théodose.

107. Claudien, Épithalame pour les noces de l'empereur Honorius 259-261: «Reçois la fortune de ta race, reprends le diadème que tu dois transmettre à tes enfants, et retourne au fond de ce palais, d'où ta mère est venue. »

108. Voir CHARLET 2000, II, p. 182, n. 2 (sur la p. 78).

109. Claudien, Épithalame pour les noces de l'empereur Honorius 309-312: « Nous pourrions dire quels combats furent menés sous l'Hémus et quelles batailles ont ensanglanté les vapeurs du Strymon, combien il est connu par son bouclier, avec quelle puissance il foudroie son ennemi, si Hymen ne nous en empêchait. »

110. La même image sera encore employée pour Stilicon dans le Contre Eutrope 2, 544.

Faut-il voir dans le curis du v. 317 une allusion aux curis [...] meis de Théodose au v. 152 du Panégyrique pour le troisième consulat d'Honorius, dont nous avons dit qu'ils pouvaient peut-être désigner, outre le soin paternel à accorder à Arcadius et Honorius, le gouvernement même de l'Empire?

111. CHARLET 2000 , II, p. 80 , note $g$. 
112. Claudien, Épithalame pour les noces de l'empereur Honorius 332-334: « Notre crainte elle-même te prouve notre amour, arbitre très juste des lois, gardien très fidèle d'une paix glorieuse, le meilleur des chefs, le plus fortuné des pères. »

113. Claudien, Épithalame pour les noces de l'empereur Honorius 338: "Qu'ainsi le petit Eucherius dépasse son père par sa valeur. »

114. Panégyrique pour le troisième consulat d'Honorius 52 ; Panégyrique pour le quatrième consulat d'Honorius 24 et 190 ; La Guerre contre Gildon 326 ; 368. Dans le second livre du Consulat de Stilicon (v. 240), le terme auus est utilisé dans la prosopopée de l'Espagne, pour désigner encore une fois Stilicon.

115. CHARLET 2000, II, p. 106.

116. Voir CHARLET 2000, II, p.185-186, n. 2 (sur la p.108): la ponctuation et l'interprétation du v. 6 posent problème. L'expression patris officiis semble maintenir une adroite ambiguïté entre Théodose et Stilicon (d'autant plus que pater est repris au v. 12 pour désigner Stilicon), dans le but de ne pas faire ouvertement de Stilicon le responsable du mariage entre Honorius et Marie.

117. Il est remarquable de voir que, au fil des poèmes politiques de Claudien, Théodose (et Théodose comes, d'ailleurs) et Stilicon partagent les mêmes appellations, non seulement pour ce qui est de leur titre de chef de guerre, mais aussi pour ce qui concerne leur statut de père. Y.-M. Duval énumère quelques-uns des termes qui sont employés par Claudien pour désigner l'Empereur (DUVAL 1984, p. 134-135) : " genitor, pater, parens, dux, princeps, rector, armipotens, Augustus, fortis, uictor", auxquels on doit ajouter socer et auus. Stilicon est appelé entre autres ductor, dux, bellipotens, socer, pater, parens. L'appellation gener, quant à elle, le rapproche d'Honorius.

118. GUIPPONI-GINESTE 2010, p. 104-105.

119. Claudien, Panégyrique pour le sixième consulat d'Honorius 587-588: "Cet enfant, le voici, qui aujourd'hui fait venir aux rostres les citoyens romains ».

120. BUREAU 2009a, p. 13 sq.

121. Sur la progression marquée entre ces deux séjours à Rome en ce qui concerne Honorius, voir GUIPPONI-GINESTE 2007, p. 10: «Ce voyage est l'accomplissement et l'achèvement des précédents. Ce séjour à Rome contraste avec la première visite décrite dans la partie de l'éloge consacrée à l'anatrophé. Honorius était dans son âge tendre, le voici iuuenis. Il était présenté au peuple et faisait l'apprentissage de sa position officielle. Le voici lui-même Empereur, reconnu par les élites et ovationné par le peuple. Il avait effectué le voyage d'Orient (Constantinople) en Occident (Milan). On le voyait notamment dans 3 cons. affronter tous les dangers pour revenir en Occident. C'était déjà préférer les beautés authentiques de l'Italie aux vains attraits de l'Orient et se rapprocher de Rome. Un deuxième pas a été franchi, dit la déesse, en allant de Milan à Ravenne, mais il lui fallait entreprendre ce dernier voyage afin d'accomplir sa destinée qui le lie à l'Vrbs. »

Le récit que donne Claudien lui-même de l'arrivée d'Honorius à Milan dans le Panégyrique pour le troisième consulat d'Honorius est d'ailleurs bien différent de celui que l'on trouve ici : par contraste, on voit à quel point, dans la seconde version, l'accent est mis sur la ciuilitas de Théodose, offerte en exemple à son fils.

122. C'est ce que Claudien lui-même affirme dans une adresse à Stilicon, dans le Consulat de Stilicon $(2,69-72)$ : secreto consona regno / ceu iunenem doceas, moles quid publica 
poscat ; / ceu sanctum uenerere senem patriisque gubernes / imperium monitis, « soit qu'à un jeune homme tu enseignes les secrets de ce qui convient au roi (quel est son devoir envers son peuple), soit qu'à un saint vieillard tu montres tout ton respect et gouvernes l'Empire en suivant les instructions d'un père ".

123. A. 9, 276 (voir DEWAR 1996, p. 101, qui rapproche aussi l'apostrophe de la Thébaïde de Stace, en 12, 73 sq.).

124. Claudien, Panégyrique pour le sixième consulat d'Honorius 54-55: «Ce sont les lieux que ton père, dans son amour pour la patrie, te donnait à admirer autrefois en tes jeunes années, et que tu réclamais pour toi. »

125. Cette scène où un roi âgé et pieux présente au nouvel arrivant une vue de Rome inspire à M. DEWAR un rapprochement avec le passage centré sur Évandre et Énée au livre 8 de l'Énéide (v. 337 sq.) : notons alors que, si Honorius était un nouvel Ascagne dans le Panégyrique pour le quatrième consulat d'Honorius (voir ci-dessus), il a donc bien grandi, et le voici en nouvel Énée (DEWAR 1996, p. 102).

126. Voir ci-dessus.

127. F. Paschoud rappelle que, pour la majorité des empereurs du $\mathrm{IV}^{\mathrm{e}} \mathrm{s}$., le centre de l'Empire est Constantinople, et non Rome: "Ce qu'il vaut la peine de souligner à nouveau, c'est que, comme Stilicon, et contrairement à la majorité des empereurs du $4^{\mathrm{e}}$ siècle, Claudien voyait sans la moindre hésitation le centre et l'avenir de l'Empire non à Constantinople, mais à Rome » (PASCHOUD 1967, p. 148-149).

128. La Guerre contre Gildon 224.

129. Avant que natoque au v. 112 ne le fasse définitivement.

130. Nous l'avons dit, Honorius nomme Stilicon sancte pater au v. 354 de La Guerre contre Gildon; aux v. 435 et 493 de ce panégyrique, c'est toujours le Prince qui en parle comme d'un parentem.

131. Le contraste est frappant avec, par ex., ces mots de l'Aurore adressés à Stilicon dans le Contre Eutrope: In te iam spes una mihi, «C'est en toi que réside désormais mon seul espoir » (v. 591) puis clipeus nos protegat idem, / unaque pro gemino desudet cardine uirtus, "qu'un même bouclier nous protège et que la valeur d'un seul œuvre au salut des pôles jumeaux du monde » (v. 601-602).

132. À propos de la piété établie comme l'un des fondements du retour d'Honorius, présenté comme un nouvel Énée, voir GUIPPONI-GINESTE 2007, p. 10.

133. De même, dans La Guerre contre Gildon (v. 49), Auguste est présenté comme un contre-exemple, pourvoyeur pour Rome d'une paix qui n'était que servile (voir CHARLET 2000, II, p. 202-203, n. 4 [sur la p. 125]; la présence d'Auguste, fero [...] Caesar, s'inscrit dans un long passage où Rome donne les raisons de sa propre décadence: la confiscation des droits des citoyens par Auguste est la première énoncée). Bien que les occurrences en soient plus rares (contrairement à ce qui se passe chez Pline, qui dans son panégyrique use volontiers de la figure de Domitien comme contre-exemple opposé à Trajan ; voir ROCHE 2011, p. 10-14), Claudien présente en effet certains empereurs, non pas en modèles, mais en contre-modèles : c'est aussi le cas de Néron et de Tibère dans le Panégyrique pour le quatrième consulat d'Honorius (v. 313-315), et dans le livre 2 du Contre Eutrope (v. 62). Toujours dans le Contre Eutrope, la réécriture de la satire 4 de Juvénal évoque avec elle l'image de Domitien: le passage actualise sous les yeux de l'auditoire le triste tableau que peignent les Satires, et notamment l'honneur et la richesse 
confondus, et la terreur qui se masque d'hypocrisie (sur ce passage et ses liens avec la satire du turbot, voir Garambois-Vasquez 2007). En outre, le Contre Rufin, La Guerre contre Gildon et le Contre Eutrope contribuent à faire le portrait du modèle à ne pas suivre, celui du tyran oriental. C'est que Claudien ne cache pas le fait que la fonction impériale ne met pas à l'abri des excès. Bien plus, ces allusions fonctionnent comme des mises en garde : on court le risque de devenir un mauvais empereur si l'on ne choisit pas de se référer au mos maiorum.

134. Claudien, Panégyrique pour le sixième consulat d'Honorius 331-332 : «Entre-temps le désir de voir le Prince se fait plus ardent et enflamme les Pères avec le peuple ».

135. Claudien, Panégyrique pour le sixième consulat d'Honorius 581-583: «et que tu rappelais dans ton cœur le jour fameux où, au milieu de l'incertitude et des troubles de l'épouvante, le père à l'agonie te confia l'éducation de son enfant ".

136. Voir CAMERON 1970, p.49-52. A. Cameron y aborde le fait que Claudien a constamment cherché à légitimer la régence de Stilicon sur les deux parties de l'Empire («Stilico's supreme goal was to unite both halves under his regency», p. 51), tout du moins jusqu'en 402 : le thème disparaît en effet de ses œuvres ultérieures. Il explique cela par le fait qu'à partir de cette époque, et à cause de l'âge d'Arcadius, Stilicon ne peut plus espérer exercer la régence en Orient: "by 402 Stilico had virtually abandoned all hope of ever establishing his regency over the then 26-year-old Arcadius » (p. 50).

137. Et l'hommage est tout de même assez solennel pour que l'on ait ici la seule occurrence d'une apostrophe du poète à Stilicon dans un panégyrique impérial. Néanmoins, il semble que le rôle paternel de Stilicon envers Honorius s'estompe dans ce poème-ci : il est toujours celui à qui Théodose a demandé de veiller sur son fils, mais son statut est plutôt celui d'un guide qui demeure aux côtés de l'Empereur. Cela apparaît notamment dans l'accent mis sur Honorius vengeur de son père : la relation entre père et fils se fait plus immédiate.

138. Y.-M. Duval montre bien comment la scène du double triomphe fonctionne en écho avec la description de l'aduentus de 389, autrement dit comment Stilicon apparaît ici comme endossant la charge qui était auparavant celle de Théodose (DUVAL 1984, p. 176-180).

139. L'idée est déjà présente dans le Panégyrique pour le quatrième consulat d'Honorius, mais l'immaturité du Prince y est bien plus mise en avant.

140. Sur la clémence de Marc Aurèle, voir CAMERON 1970, p. 212-213. Sur la clémence chez les empereurs depuis Auguste comme vertu cardinale, à la fois philosophique et pragmatique, voir DEWAR 1996, p. 259-260.

141. Claudien, Le Consulat de Stilicon 1,193 : «Que tes guerres, Drusus, que les tiennes, Trajan, se retirent $»$.

142. CHARLET 2009, p. 562, en référence aux v. 315-319 du Panégyrique pour le quatrième consulat d'Honorius.

143. Qui, lui aussi, reçoit l'épithète bellipotens, voir ci-dessus.

144. Au v. 550, c'est d'ailleurs Honorius qui sera qualifié de clemens.

145. Sur l'édification de cet autel, voir par ex. A Topographical Dictionary of Ancient Rome de S. B. PLATNER, revu et complété par T. ASHBY, Londres, Oxford University Press, 1929, p. 218. 
146. Voir GUIPPONI-GINESTE 2007, p. 2, qui cite J. CHAMPEAUX, Fortuna. Recherches sur le culte de la Fortune à Rome et dans le monde romain des origines à la mort de César, Coll. de l'École française de Rome 64, Rome, École française de Rome, 1982-1987, 2 vol.

147. Ce passage n'est pas le seul où Pacatus traite de la vertu de Théodose qui lui a valu son titre d'empereur. Voir DEWAR 1996, p. 296-300, pour d'autres liens textuels. Mais on retrouve ici à la fois une situation d'énonciation similaire, le thème du refus de la part de l'Empereur, et la suite des noms des grands empereurs.

148. Pacatus y insiste d'ailleurs sur l'extrême jeunesse de Valentinien II : Principum senior in tanta bella non sufficit, alter, etsi futurus sit aliquando fortissimus, adhuc tamen paruus est, «L'ainé des princes succombe sous le poids de ces guerres; l'autre, si vaillant qu'il doive être un jour, n'est pour l'heure qu'un enfant » $(11,5)$, alors que tout l'enjeu chez Claudien est de montrer que, dorénavant, Honorius est apte à gouverner.

149. À l'inverse, dans la prosopopée que Rome adresse à Honorius et à Stilicon à la fin du livre 1 du Contre Eutrope, les exempla concernent exclusivement le temps des rois et le temps de la République : c'est que Claudien ne s'attache pas ici à construire une figure d'empereur pour Honorius, mais à opposer la grande vertu romaine (et occidentale) à la politique orientale, qui laisse des eunuques s'élever jusqu'au consulat. La prosopopée du panégyrique pour le sixième consulat diffère également de celle de l'Aurore sur laquelle s'achève le livre 2 du Contre Eutrope, ou de celle de Rome au début du Contre Gildon. Les prosopopées des nations dans le livre 2 du Consulat de Stilicon concourent à donner du général vandale une stature impériale : Si non ut ductor ab orbe / quem regit, accipiat saltem cognatus ab aula, "Si ce n'est pas en tant que chef de la part du monde qu'il gouverne, que ce soit du moins en tant que membre de la famille de la part de la cour » (v. 236-237); mais si Rome s'indigne de le voir refuser le consulat, dans une nouvelle reprise du motif de la recusatio imperii, c'est au seul Brutus qu'elle le compare.

150. Pacatus, Panégyrique de Théodose 11, 6-7: «le pacifique Nerva, Titus l'amour du genre humain, Antonin célèbre par sa piété, au temps où Auguste me faisait une parure de vertus, où Hadrien m'initiait aux lois, où Trajan reculait mes frontières ».

151. Elle commence par comparer l'événement à trois cas précédents où un empereur s'est rendu dans la Cité (v. 392 sq.), mais c'est pour déplorer d'une part ce qui a déjà été dit plus haut par le poète sur la valeur d'un triomphe obtenu dans une guerre civile (lorsque Honorius était comparé à Auguste), et d'autre part leur superbia (v. 395). Sur la délicate identification de ces trois empereurs, qui ne sont pas nommés, voir la discussion de DEWAR 1996, p. 283-287. L'une de ces trois visites est peut-être à mettre au compte de Théodose : doit-on y voir la raison pour laquelle Claudien ne donne pas de noms ? Ou ce choix se justifie-t-il parce que, de manière générale, il préfère donner des modèles plutôt que des contre-modèles et que, quand il remonte plus loin que Théodose comes, il les choisit systématiquement dans des temps reculés de l'histoire de Rome (ZARINI 2010) ? Quoi qu'il en soit, nous avons ici une description repoussoir de l' aduentus impérial : le bon prince triomphe dans des guerres étrangères, et à la morgue il substitue la ciuilitas.

152. Le jeu des pronoms fait d'ailleurs que ces princes anonymes et l'allégorie de Rome se confondent, et la $1^{\text {re }}$ personne du pluriel dans nostram n'est peut-être pas seulement un « nous » de majesté.

153. DEWAR 1996, p. 299.

154. CHAUSSON 2007, p. 236-237. 
155. DEWAR 1996, p. 298.

156. « À en croire Claudien, les Antonins recoururent au bon jugement plutôt aux [sic] droits du sang pour choisir leurs successeurs, ce qui est faire bon marché des liens de parenté existant les [sic] divers princes de cette dynastie qui, privés de fils, furent contraints d'adopter pragmatiquement des successeurs qui d'ailleurs leur étaient souvent proches par le sang " (CHAUSSON 2007, p. 236).

157. BUREAU 2009a, p. 12.

158. C'était déjà le cas dans le Panégyrique pour le quatrième consulat d'Honorius, au v. 21.

159. Voir ci-dessus.

160. BRAUND 1998.

161. BRAUND 1998, p. 66.

162. On lit aux v. 424-425 le passage du tenero [...] aeuo au iuuenem : Claudien décrit un Honorius sur le point de prendre son envol, et qui est sommé de le faire car le temps passe. Nous avons sous les yeux la transformation d'un puer en princeps, mais qui n'est pas encore affranchi de la tutelle de Stilicon (duce [...] socero). On voit bien qu'il n'est pas question d'évacuer Stilicon, tout le monde s'accorde à le louer : Claudien, Théodose, Alaric, Honorius. Mais maintenant qu'Honorius est en âge de régner, le lien familial qui unit les deux hommes prend une importance cruciale pour ce qui est d'expliquer pourquoi ce sont eux qui se retrouvent aujourd'hui à la tête de l'Empire. Aussi Stilicon est-il presque systématiquement accompagné de son titre de gener (de Théodose) ou de socer (d'Honorius).

163. BUREAU 2009b, p. 299-313.

164. Dans le Panégyrique pour le troisième consulat d'Honorius, Claudien use des apostrophes suivantes pour s'adresser à Honorius (ou à Honorius et son frère, dans le cas de la dernière) : o qui patrium curis aequalibus orbem / Eoo cum fratre regis (v. 7-8) ; spes uotumque poli (v.10); o nimium dilecte Deo (v.96); unanimi fratres (v. 189). Dans le Panégyrique pour le quatrième consulat d'Honorius, le poète n'use d'aucune apostrophe à l'intention de l'Empereur.

165. G. Serbat (1996, p. 90) indique comme étant l'une des fonctions du vocatif, quand le contact et le dialogue entre les interlocuteurs sont déjà entamés, le fait de s'assurer de l'attention de l'autre interlocuteur. Mais le vocatif en a d'autres, et notamment celle qui consiste à exprimer un jugement, élogieux ou dépréciatif, vis-à-vis de l'interlocuteur : se superpose à l'appel une information ou un commentaire sur une qualité qui appartient en propre au destinataire et le définit comme pourrait le faire son nom, de manière subjective bien sûr. Un peu plus loin (p.98), il ajoute la fonction d'affirmer solennellement ou de prendre à témoin (une divinité, généralement, mais pas toujours) : dans ce cas, le vocatif n'est pas le vrai destinataire de l'énoncé.

166. J. L. Austin (1970) définit ainsi l'énonciation performative, par rapport à l'énonciation constatative : il s'agit d'une énonciation ni vraie ni fausse, ni un non-sens, mais une énonciation visant à faire quelque chose. Elle conduit donc à l'échec ou à la réussite, et non à la vérité ou à la fausseté. Or le panégyrique, en entraînant un discours idéal dont le contenu, qui peut déformer les faits, est subordonné à l'exposé des qualités du sujet choisi, est propice à de tels effets.

167. Nous ne partageons donc pas les vues d'A.Cameron quand il affirme que les conseils donnés directement au Prince n'avaient pas pour but d'être pris au sérieux, et 
que Claudien se proposait à travers eux, non pas d'instruire, mais de divertir. En effet, il ne voit dans leur contenu aucun risque d'offense, mais bien plutôt des lieux communs du peri basileias (CAMERON 1970, p. 431 sq.). Quant à la figure du prince-ciues qui traverse le Panégyrique pour le sixième consulat d'Honorius, il l'explique simplement par la venue d'Honorius à Rome (Claudien représente Honorius en citoyen uniquement parce qu'il est à Rome) : elle ne serait donc pas le fruit d'une vision politique réfléchie. Il affirme par ex. que Claudien a repris à Pacatus l'idée qu'à Rome l'Empereur devait se comporter comme les Romains, autrement dit faire preuve de ciuilitas (CAMERON 1970, p. 383), ce qui l'amène à évacuer le sens d'une telle représentation. Or la cohérence des conceptions politiques décrites dans cet ultime poème avec celles des œuvres qui précèdent nous paraît contredire une telle opinion. À la leçon de Théodose dans le Panégyrique pour le quatrième consulat d'Honorius répond celle de Rome dans le panégyrique pour le sixième consulat. Les derniers vers de Claudien invitent Honorius à devenir à son tour un modèle : hunc et quinque tui uel quos habiturus in urbe / post alios, Auguste, colant. Licet unus in omnes / consul eas, magno sextus tamen iste superbit/ nomine: praeteritis melior, uenientibus auctor, «que tes cinq consulats précédents, ainsi que ceux que tu exerceras à l'avenir dans Rome, Empereur Auguste, cèdent le pas à celui-ci : serais-tu consul chaque année que ce serait cependant ce sixième consulat qui surpasserait les autres de son nom illustre, meilleur que ceux qui ont déjà eu lieu, et modèle de ceux à venir ». Ils marquent bien que ce consulat doit être non seulement meilleur (ce qui pourrait être une façon de sacrifier au topos de la surenchère), mais aussi différent. La toute fin du panégyrique pour Manlius Theodorus semble se rapprocher d'un tel discours : Accipiat patris exemplum tribuatque nepoti / filius et coeptis ne desit fascibus heres. / Decurrat trabeata domus tradatque secures/ mutua posteritas seruatoque ordine fati/ Manlia continuo numeretur consule proles, «Que le fils reçoive l'exemple du père et l'offre au petit-fils, et que ces jeunes faisceaux ne manquent jamais d'héritiers. Que cette maison conserve la trabée, que chacun de tes descendants transmette sa puissance au suivant, et que, dans l'ordre voulu par le destin, la lignée de Manlius ajoute continuellement à la suite des consuls » (v. 336-340). Mais l'exemple que représente le consul est limité à sa seule lignée familiale. Dans le Panégyrique pour le sixième consulat d'Honorius, le modèle est à la fois le consulat endossé par Honorius en cette année 404, mais aussi potentiellement le texte même du panégyrique (sextus [...] iste), destiné à inspirer les autres consulats à venir (uenientibus auctor). La fin du Panégyrique pour le sixième consulat d'Honorius est de fait la seule occurrence que nous ayons d'une conclusion qui soit ainsi programmatique.

168. PERNOT 2015, p. 102 sq.

\section{RÉSUMÉS}

Les poèmes politiques que Claudien a écrits pour l'empereur Honorius sont émaillés de références à des empereurs antérieurs, parmi lesquels Théodose, son père, et Trajan, modèle achevé de l'optimus princeps. L'objet de cet article est d'étudier comment, au travers de ces références, le poète entreprend de dessiner pour le tout jeune Prince d'Occident la figure du bon 
empereur et de définir sa légitimité (ainsi que celle du régent Stilicon, qu'aucune disposition légale ne justifie) entre transmission dynastique du pouvoir et choix du meilleur. Se voit ainsi précisé le fonctionnement du panégyrique impérial, qui ne se limite pas chez Claudien à la simple louange : le discours crée et met en forme sa propre réalité, jusqu'à se faire performatif et modeler le personnage loué. La perspective chronologique qui a été choisie montre en outre l'évolution du propos de Claudien à mesure qu'Honorius passe de l'enfance à l'âge adulte.

Several references to earlier emperors can be found in Claudian's politic poems addressed to Emperor Honorius; among them are Theodosius, his father, and Trajan, the model for the optimus princeps. This paper aims at analysing how the poet makes use of these references to show the very young Prince of the West what a good emperor is and to legitimatize him (and, at the same time, to legitimatize Stilicho's place, which has no legal basis): to achieve this goal, Claudian draws on the double idea of the dynastic transfer of imperial power and the choice of the best possible man. Analysing this allows a better understanding of the functioning of the imperial panegyric, which goes beyond the mere praise in Claudian's poetry: it creates and shapes the reality it describes - and so the figure of the Prince- in a performative way. The chronological perspective of this study shows also how Claudian's discourse evolves as Honorius grows from childhood to maturity.

\section{INDEX}

oeuvrecitee Histoire Auguste

Index géographique : Constantinople, Espagne, Milan, Orient, Ravenne, Rome

nomsmotscles Claudien, Dion Cassius, Drepanius (Latinus Pacatus), Jérôme, Juvénal, Pline le Jeune, Sénèque, Stace, Synésios de Cyrène, Thémistius, Virgile

Mots-clés : éloge, énonciation, épithalame, exemplum, idéologie dynastique, idéologie impériale romaine, littérature et politique, miroir des princes, panégyrique, Princeps, propagande politique, rhétorique, uirtutes

Keywords : dynastic ideology, enunciation, epithalamium, exemplum, literature and politics, mirror of princes, panegyric, political propaganda, praise, Princeps, rhetoric, Roman imperial ideology, uirtutes

\section{AUTEURS}

\section{CHARLOTTE TOURNIER}

Université Lille 3 Charles de Gaulle, UMR 8164 HALMA 